\title{
Performance Evaluation of Spectroscopic Detectors for LEU Hold- up Measurements
}

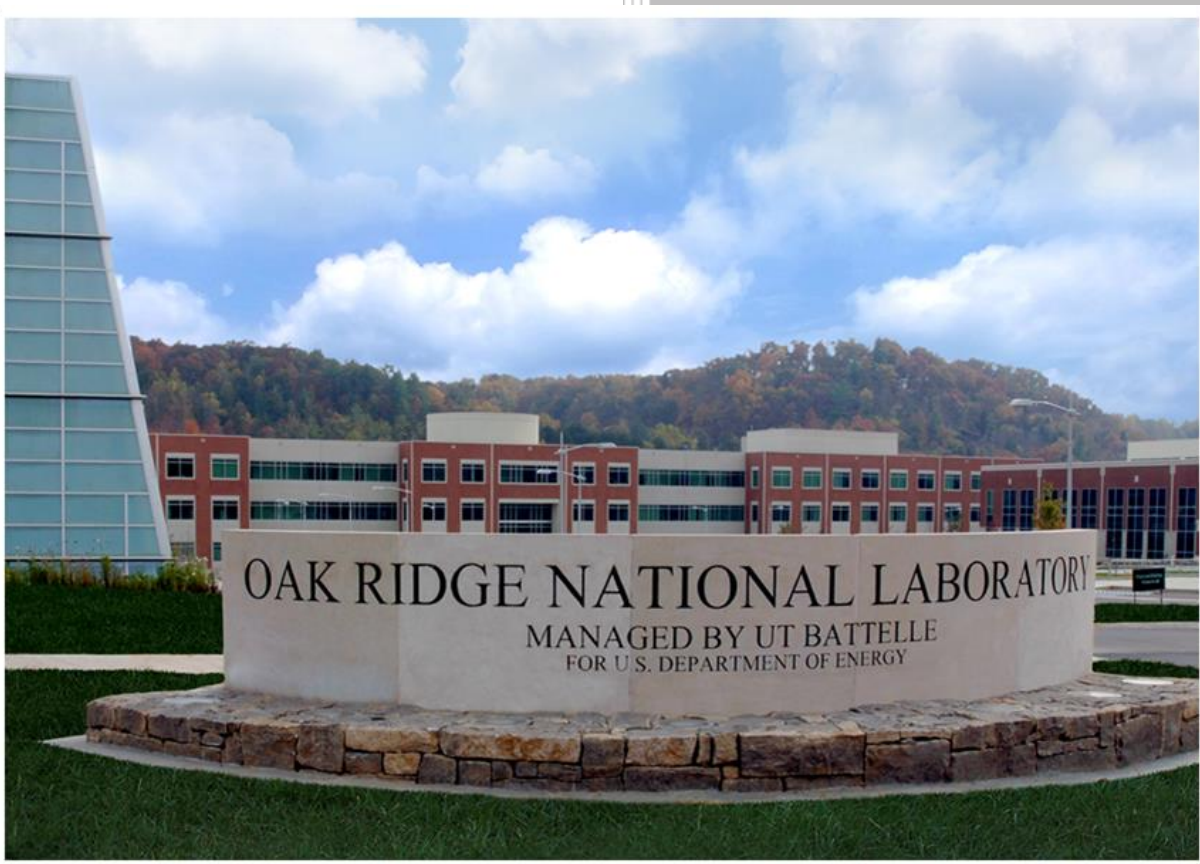

Approved for public release. Distribution is unlimited

Ramkumar Venkataraman Greg Nutter Robert McElroy

December 6, 2016 


\title{
DOCUMENT AVAILABILITY
}

Reports produced after January 1, 1996, are generally available free via US Department of Energy (DOE) SciTech Connect.

Website http://www.osti.gov/scitech/

Reports produced before January 1, 1996, may be purchased by members of the public from the following source:

\author{
National Technical Information Service \\ 5285 Port Royal Road \\ Springfield, VA 22161 \\ Telephone 703-605-6000 (1-800-553-6847) \\ TDD 703-487-4639 \\ Fax 703-605-6900 \\ E-mail info@ntis.gov \\ Website http://www.ntis.gov/help/ordermethods.aspx
}

Reports are available to DOE employees, DOE contractors, Energy Technology Data Exchange representatives, and International Nuclear Information System representatives from the following source:

Office of Scientific and Technical Information

PO Box 62

Oak Ridge, TN 37831

Telephone 865-576-8401

Fax 865-576-5728

E-mail reports@osti.gov

Website http://www.osti.gov/contact.html

This report was prepared as an account of work sponsored by an agency of the United States Government. Neither the United States Government nor any agency thereof, nor any of their employees, makes any warranty, express or implied, or assumes any legal liability or responsibility for the accuracy, completeness, or usefulness of any information, apparatus, product, or process disclosed, or represents that its use would not infringe privately owned rights. Reference herein to any specific commercial product, process, or service by trade name, trademark, manufacturer, or otherwise, does not necessarily constitute or imply its endorsement, recommendation, or favoring by the United States Government or any agency thereof. The views and opinions of authors expressed herein do not necessarily state or reflect those of the United States Government or any agency thereof. 
Nuclear Security and Isotope Technology Division - Safeguards and Security Technology Group

Performance Evaluation of Spectroscopic Detectors for LEU Hold-up Measurements

\author{
Ramkumar Venkataraman, Greg Nutter, Robert McElroy
}

Date Published: December 6, 2016

Prepared by OAK RIDGE NATIONAL LABORATORY

Oak Ridge, TN 37831-6283

managed by

UT-BATTELLE, LLC

for the

US DEPARTMENT OF ENERGY

under contract DE-AC05-00OR22725 



\section{CONTENTS}

CONTENTS

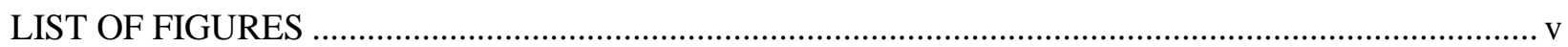

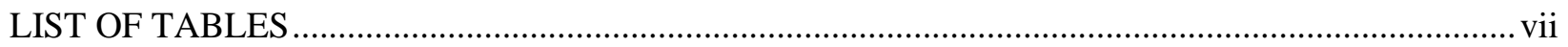

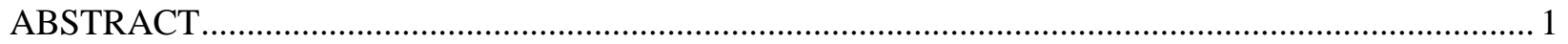

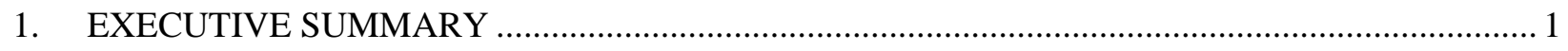

2. OVERVIEW OF THE MEASUREMENT CAMPAIGN .......................................................... 3

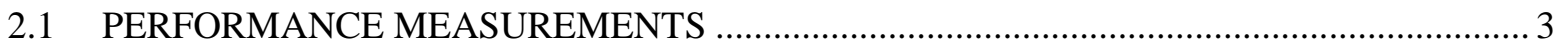

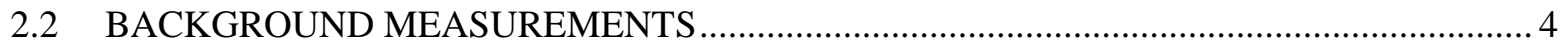

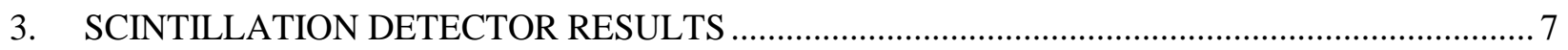

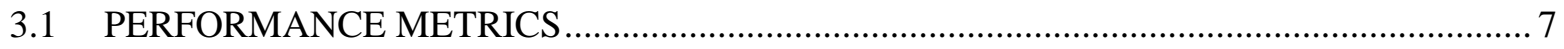

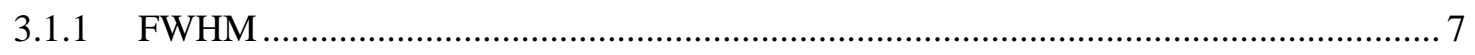

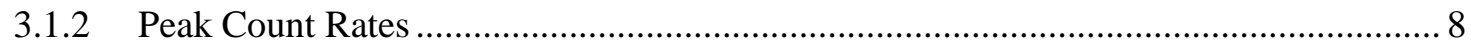

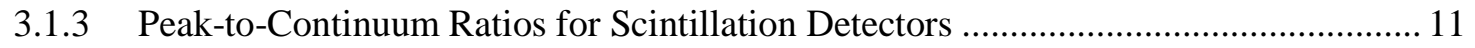

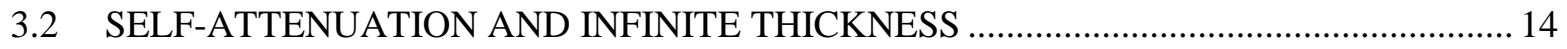

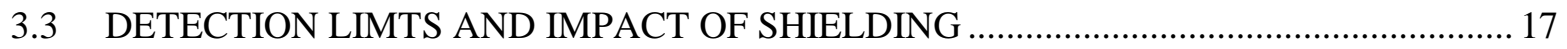

3.4 GAIN STABILIZATION OF SCINTILLATION DETECTOR RESPONSE ...................... 20

3.4.1 Gain Stabilization Using an LED-Based Approach................................................ 20

3.4.2 Gain Stabilization Using an ${ }^{241}$ Am Seed in the Scintillation Crystal ...................... 22

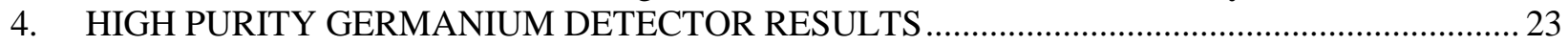

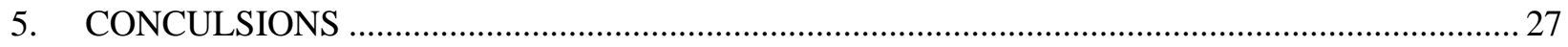

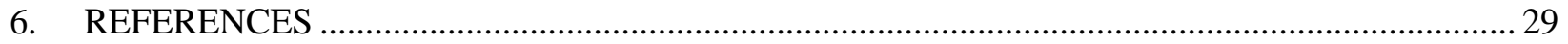





\section{LIST OF FIGURES}

Figure 1. Measurement setup to count the NBL standard sources....................................................... 4

Figure 2. Intrinsic background from $1.5 \times 1.5$ in. $\mathrm{LaBr}_{3}(\mathrm{Ce})$ detector collected for 57,600 sec. (16

hr.).

Figure 3. FWHM results for evaluated scintillation detectors. ....................................................... 7

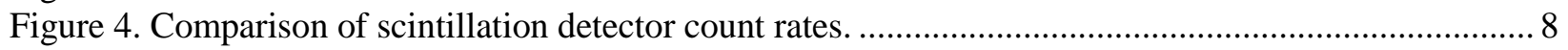

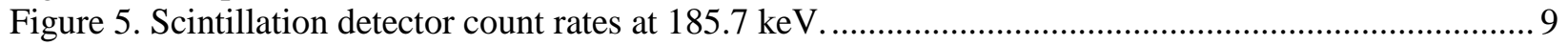

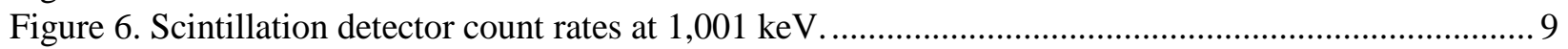

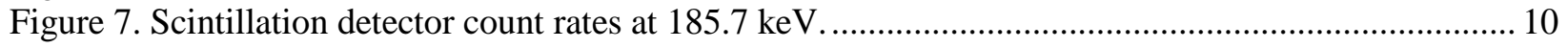

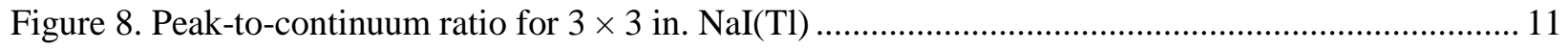

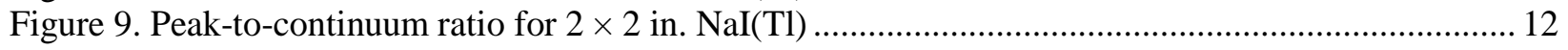

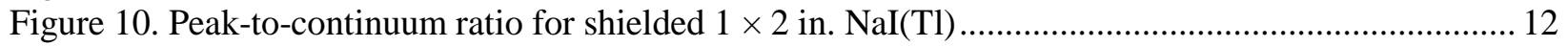

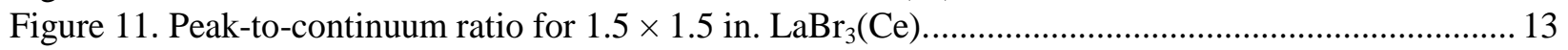

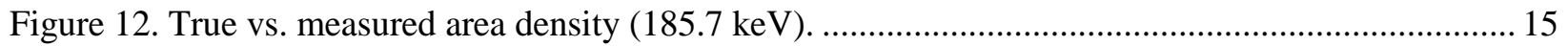

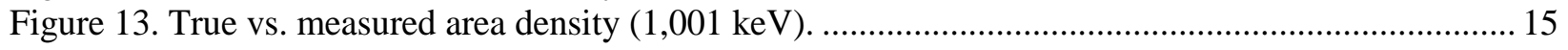

Figure 14. Self-attenuation correction factor vs. true area density $(185.7 \mathrm{keV})$. ................................ 16

Figure 15. Self-attenuation correction factor vs. true area density $(1,001 \mathrm{keV})$................................... 17

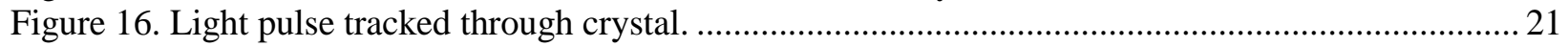

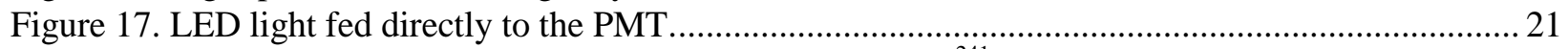

Figure 18. Gain stabilization using the $3.3 \mathrm{MeV}$ GEE peak from ${ }^{241} \mathrm{Am}$ seed. ...................................... 22

Figure 19. NBL can measurement using the BE3820 detector and ISOCS shield. ................................2

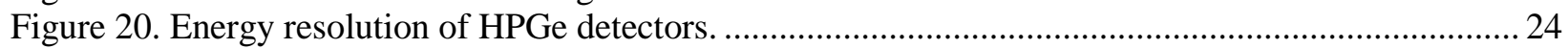

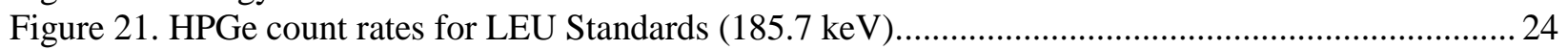

Figure 22. HPGe Count rates for LEU Standards $(1,001 \mathrm{keV})$............................................................ 25 



\section{LIST OF TABLES}

Table 1. Detectors and MCAs used in the evaluation....................................................................... 3

Table 2. Minimum detectable quantities using various detector types and sizes $(186 \mathrm{keV})$.................... 19

Table 3. Minimum detectable quantities using various detector types and sizes $(1,001 \mathrm{keV})$................. 19

Table 4. Impact of shielding on MDA and the weight of the probe .....................................................2 20

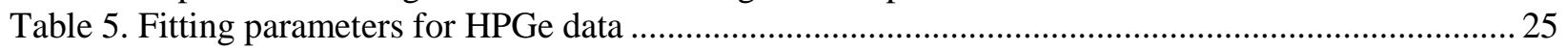





\begin{abstract}
The hold-up measurement of low enriched uranium materials may require use of alternate detector types relative to the measurement of highly enriched uranium. This is in part due to the difference in process scale (i.e., the components are generally larger for low enriched uranium systems) but also because the characteristic gamma-ray lines from ${ }^{235} \mathrm{U}$ used for assay of highly enriched uranium will be present at a much reduced intensity (on a per gram of uranium basis) at lower enrichments. Researchers at Oak Ridge National Laboratory examined the performance of several standard detector types, e.g., $\mathrm{NaI}(\mathrm{Tl})$, $\mathrm{LaBr}_{3}(\mathrm{Ce})$, and HPGe, to select a suitable candidate for measuring and quantifying low enriched uranium hold-up in process pipes and equipment at the Portsmouth gaseous diffusion plant. Detector characteristics, such as energy resolution (full width at half maximum) and net peak count rates at gamma ray energies spanning a range of $60-1332 \mathrm{keV}$, were measured for the above-mentioned detector types using the same sources and in the same geometry. Uranium enrichment standards (Certified Reference Material no. 969 and Certified Reference Material no. 146) were measured using each of the detector candidates in the same geometry. The net count rates recorded by each detector at $186 \mathrm{keV}$ and $1,001 \mathrm{keV}$ were plotted as a function of enrichment (atom percentage). Background measurements were made in unshielded and shielded configurations under both ambient and elevated conditions of ${ }^{238} \mathrm{U}$ activity.

The highly enriched uranium hold-up measurement campaign at the Portsmouth plant was performed on process equipment that had been cleaned out. Therefore, in most cases, the thickness of the uranium deposits was less than the "infinite thickness" for the $186 \mathrm{keV}$ gamma rays to be completely selfattenuated. Because of this, in addition to measuring the $186 \mathrm{keV}$ gamma, the $1,001 \mathrm{keV}$ gamma ray from ${ }^{234 \mathrm{~m}} \mathrm{~Pa}$ - a daughter of ${ }^{238} \mathrm{U}$ in secular equilibrium with its parent-will also need to be measured. Based on the performance criteria of detection efficiency, energy resolution, peak-to-continuum ratios, minimum detectable limits, and the weight of the shielded probe, a shielded ( 0.5 in. thick lead shield) $2 \times 2$ in.

$\mathrm{NaI}(\mathrm{Tl})$ detector is recommended for use. The recommended approach is to carry out analysis using data from both $186 \mathrm{keV}$ and $1,001 \mathrm{keV}$ gamma rays, and select a best result based on propagated uncertainty estimates. It is also highly recommended that a two-point gain stabilization scheme based on an ${ }^{241} \mathrm{Am}$ seed embedded in the probe be implemented. Shielding configurations to reduce the impact of background interference on the measurement of 1,001 keV gamma-ray are discussed.
\end{abstract}

\title{
1. EXECUTIVE SUMMARY
}

ORNL examined the performance of several standard detector types, e.g., $\mathrm{NaI}(\mathrm{Tl}), \mathrm{LaBr}_{3}(\mathrm{Ce})$, and $\mathrm{HPGe}$, to select the most suitable candidate to measure and quantify low enriched uranium (LEU) hold-up in the process pipes and equipment at the Portsmouth gaseous diffusion facility. Detector characteristics, such as energy resolution (full width at half maximum [FWHM]) and net peak count rates at gamma ray energies spanning a range of 60-1332 keV, were measured for the above-mentioned detector types using the same sources and in the same geometry. Certified Reference Material (CRM) 969 and CRM 146 were measured using each of the detector candidates in the same geometry. The net count rates recorded by each detector at $186 \mathrm{keV}$ and $1,001 \mathrm{keV}$ were plotted as a function of enrichment (atom percentage). Background measurements were made in unshielded and shielded configurations under both ambient and elevated conditions of ${ }^{238} \mathrm{U}$ activity. Performance criteria such as efficiency, energy resolution, and the peak-to-continuum ratios were considered at the gamma ray energies of interest, namely $186 \mathrm{keV}$ and $1,001 \mathrm{keV}$. The performance was evaluated as a function of uranium enrichment.

The highly enriched uranium (HEU) hold-up measurement campaign at the Portsmouth plant was performed on process equipment that had been cleaned out. Therefore, in most cases, the thickness of the uranium deposits was less than the "infinite thickness" for the $186 \mathrm{keV}$ gamma rays to be completely self- 
attenuated. This may not be the case in the LEU hold-up measurement campaign. Because of this, the analysis will need to be carried out on the $1,001 \mathrm{keV}$ gamma ray from ${ }^{234 \mathrm{~m}} \mathrm{~Pa}$ - a daughter of ${ }^{238} \mathrm{U}$ in secular equilibrium with its parent. Based on the performance criteria of detection efficiency, energy resolution, peak-to-continuum ratios, minimum detectable limits, and the weight of the shielded probe, a shielded ( 0.5 in. thick lead shield) $2 \times 2$ in. $\mathrm{NaI}(\mathrm{Tl})$ detector is recommended for use. The recommended approach is to carry out analysis using data from both $186 \mathrm{keV}$ and $1,001 \mathrm{keV}$ gamma rays, and select a best result based on propagated uncertainty estimates.

It is also highly recommended that a multi-channel analyzer (MCA) that uses a robust gain stabilization scheme be used for the LEU measurements, and indeed for all hold-up applications. In the probes used for measuring HEU hold-up based on the signal from the $186 \mathrm{keV}$ gamma, an adequate gain stabilization was effected using the $60 \mathrm{keV}$ gamma ray peak from an ${ }^{241} \mathrm{Am}$ source attached to the front of the probe. In the case of LEU hold-up, it may be necessary to measure the $1,001 \mathrm{keV}$ gamma ray. A two-point stabilization scheme using an ${ }^{241} \mathrm{Am}$ seed would be ideal.

The $3 \times 3$ in. $\mathrm{NaI}(\mathrm{Tl})$ detector had the best efficiency, lowest detection limits for the 1,001 keV gamma rays, the highest peak-to-continuum ratio at $1,001 \mathrm{keV}$, and an adequate energy resolution. However, the shielding around the $3 \times 3$ in. $\mathrm{NaI}(\mathrm{Tl})$ will weigh $8.65 \mathrm{~kg}$ for a thicknesses of only $0.5 \mathrm{in}$. At these weight levels, the probe will be too heavy to be carried by hand. A mobile platform on which the detector and the shield can be mounted could be a solution. The impact of this requirement must be considered by facility operations personnel to determine if this is a practical solution. It should be noted that using the larger detector $-3 \times 3$ in. $\mathrm{NaI}(\mathrm{Tl})$ with 0.5 in. lead shield - is only necessary when performing confirmatory measurements with a greater precision. 


\section{OVERVIEW OF THE MEASUREMENT CAMPAIGN}

The detector types evaluated at Oak Ridge National Laboratory (ORNL) and the corresponding MCAs are given in Table 1 below.

Table 1. Detectors and MCAs used in the evaluation

\begin{tabular}{ll}
\hline \multicolumn{1}{c}{ Detector Type } & \multicolumn{1}{c}{ Multi-Channel Analyzer } \\
\hline $1 \times 2$ in. $\mathrm{NaI}(\mathrm{Tl})$ & Ortec DigiDart MCA with Detector Interface Module \\
$2 \times 2$ in. $\mathrm{NaI}(\mathrm{Tl})$ detector & Ortec tube base MCA \\
$3 \times 3$ in. $\mathrm{NaI}(\mathrm{Tl})$ detector & Canberra Osprey tube base MCA \\
$1.5 \times 1.5$ in. $\mathrm{LaBr}_{3}(\mathrm{Ce})$ detector & Canberra Osprey tube base MCA \\
HPGe: Canberra BEGe 3825 commonly used with ISOCS & Inspector-2000 DSP \\
HPGe: Ortec Detective & Detective's MCA \\
\hline
\end{tabular}

\subsection{PERFORMANCE MEASUREMENTS}

Baseline performance of the detectors was established by measuring the FWHM at various energies in the $60-1332 \mathrm{keV}$ range. Button sources of various nuclides were used in this campaign. The same sources were used in all detector measurements, and the source-to-detector distance was maintained at $300 \mathrm{~mm}$ in all cases. The relative comparison of the net peak count rates from different detectors serves as a means for inter-comparison. With the exception of the $1 \times 2 \mathrm{in}$. $\mathrm{NaI}(\mathrm{Tl})$, all other detectors were unshielded.

Measurements were made using the uranium enrichment standards CRM 969 (LEU set) and CRM 146 (HEU set) supplied by New Brunswick Laboratory (NBL). The standard sources are aluminum cylinders with the uranium $\left(\mathrm{U}_{3} \mathrm{O}_{8}\right)$ layer present at the bottom. The diameter of the $\mathrm{U}_{3} \mathrm{O}_{8}$ layer is about $70 \mathrm{~mm}$, and its thickness is either $20.8 \mathrm{~mm}$ or $15.8 \mathrm{~mm}$ depending on the specific standard. The areal density of the $\mathrm{U}_{3} \mathrm{O}_{8}$ layer is $5.2 \mathrm{~g} / \mathrm{cm}^{2}$ for the LEU standards and $5.98 \mathrm{~g} / \mathrm{cm}^{2}$ for the HEU standards and is infinitely thick to the $186 \mathrm{keV}$ gamma rays. The aluminum walls at the bottom of the NBL standards are relatively thin $(2 \mathrm{~mm})$ so as to allow the $186 \mathrm{keV}$ gamma rays to be transmitted through the container walls. The NBL source was positioned end-on and on-axis with respect to the detector. The source-to-detector distance was maintained at $400 \mathrm{~mm}$ for all NBL standard and detector combinations. A photograph of the set-up is shown in Figure 1. 


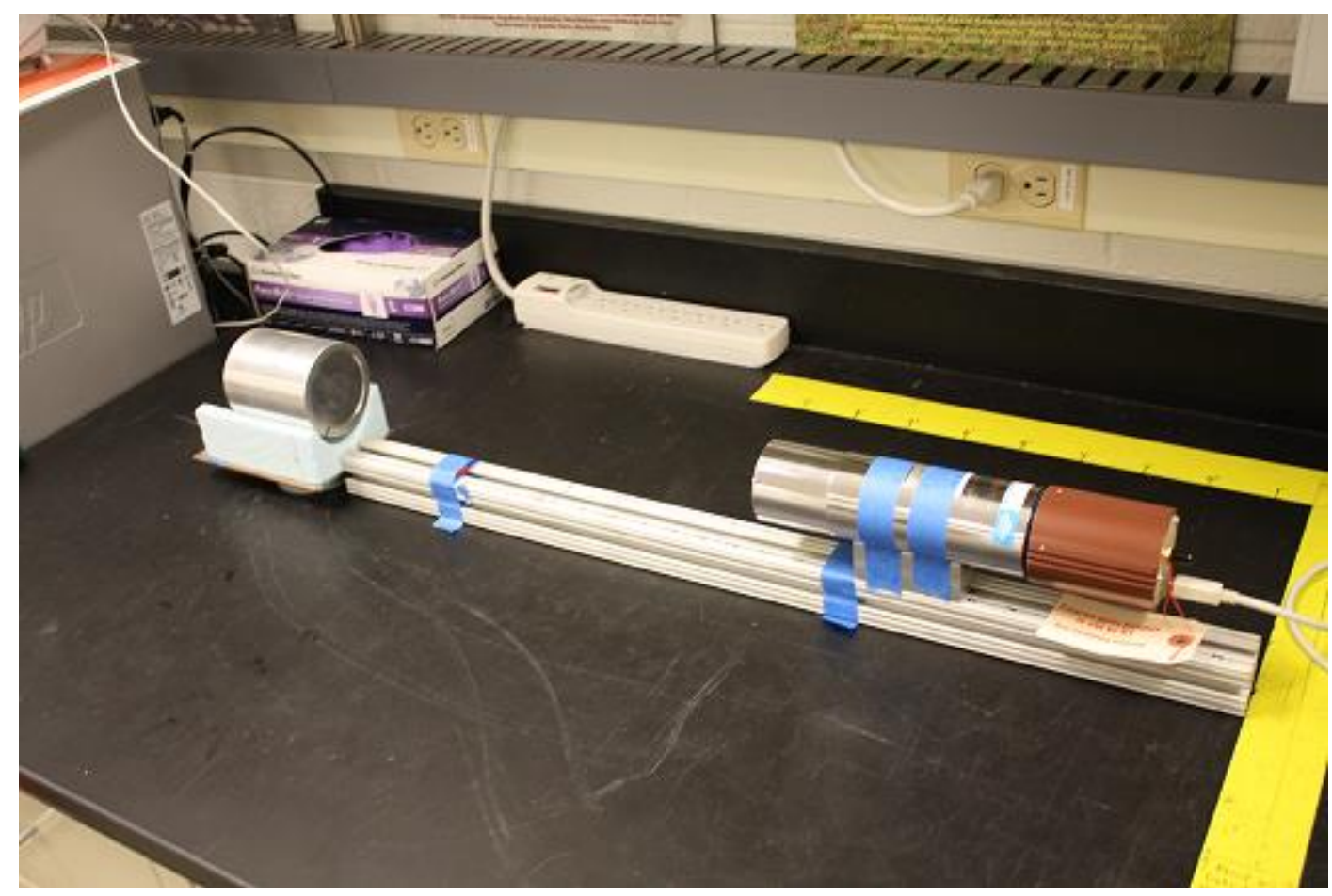

Figure 1. Measurement setup to count the NBL standard sources.

Spectra from various detectors collected using the NBL standard with a ${ }^{235} \mathrm{U}$ enrichment of $4.52 \%$ are presented in APPENDIX A.

\subsection{BACKGROUND MEASUREMENTS}

Overnight background measurements were performed on a routine basis to monitor the fluctuation in the ambient background and to ensure that there was no interference from other sources of radiation.

Measurements were also performed to determine the impact of shielding on the $1,001 \mathrm{keV}$ gamma ray from ${ }^{234 \mathrm{~m}} \mathrm{~Pa}$ (daughter of ${ }^{238} \mathrm{U}$ ) that may be present in the background. A scenario of elevated background $1,001 \mathrm{keV}$ gamma rays was simulated with the NBL standard by placing natural uranium oriented orthogonally to the detector at a distance of $30 \mathrm{~cm}$ from the side of the detector. Measurements were performed with no shielding, with a shadow shield of $0.5 \mathrm{in}$. thick lead, and with $0.0625 \mathrm{in}$. steel and 0.0625 in. copper liners.

Intrinsic background radiation is present in the $\mathrm{LaBr}_{3}(\mathrm{Ce})$ crystal from the naturally occurring radioactive isotope ${ }^{138} \mathrm{La}$ and ${ }^{227} \mathrm{Ac}$ impurities. This adds to the Compton continuum at energies below $1500 \mathrm{keV}$, thereby degrading the sensitivity of the detector. The intrinsic background was measured by counting the $\mathrm{LaBr}_{3}(\mathrm{Ce})$ detector inside a fully shielded 1 in. thick lead enclosure. The intrinsic background spectrum from $\mathrm{LaBr}_{3}(\mathrm{Ce})$ is shown in Figure 2. The peak region at 1,001 keV is highlighted. The peak region represents a width of \pm 2 FWHM, which covers $99.7 \%$ of the full energy peak at $1,001 \mathrm{keV}$. The average continuum count rate at the $1,001 \mathrm{keV}$ is 0.91 counts per second. According to the manufacturer of $\mathrm{LaBr}_{3}(\mathrm{Ce})$, Saint Gobain Crystals, the count rate, due to intrinsic background in the continuum region from $789 \mathrm{keV}$ to $1000 \mathrm{keV}$, is 0.065 counts per second, per $\mathrm{cm}^{3}$ of active crystal volume ("BrilLanCe Scintillators Performance Summary" 2009). For a $1.5 \times 1.5$ in. $\mathrm{LaBr}_{3}$ crystal of active volume $43.43 \mathrm{~cm}^{3}$, the intrinsic background works out to be 2.82 counts per second-a value much higher than what was measured at ORNL. The lower background from the ORNL detector could be due to better crystal quality. 


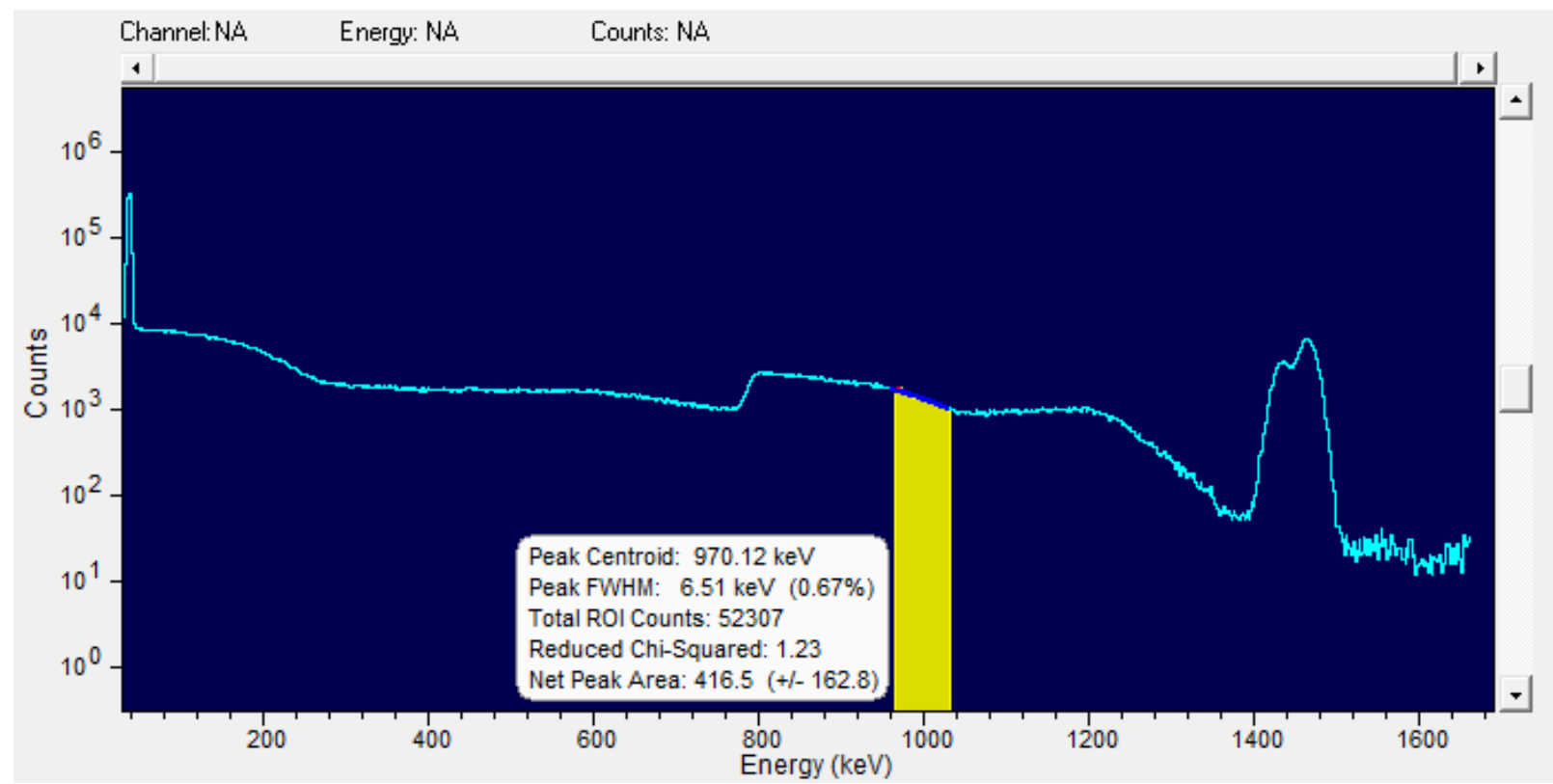

Figure 2. Intrinsic background from $1.5 \times 1.5$ in. $\mathrm{LaBr}_{3}(\mathrm{Ce})$ detector collected for $57,600 \mathrm{sec} .(16 \mathrm{hr}$.$) .$ 



\section{SCINTILLATION DETECTOR RESULTS}

For performance metrics, the comparison of the scintillation detectors primarily relied on FWHM, net peak counts, and peak-to-continuum counts. Gain stabilization methods and shielding used by each of the scintillation detectors were also evaluated.

\subsection{PERFORMANCE METRICS}

\subsubsection{FWHM}

The FWHM results for the various scintillation detectors measured are plotted as function of energy in Figure 3.

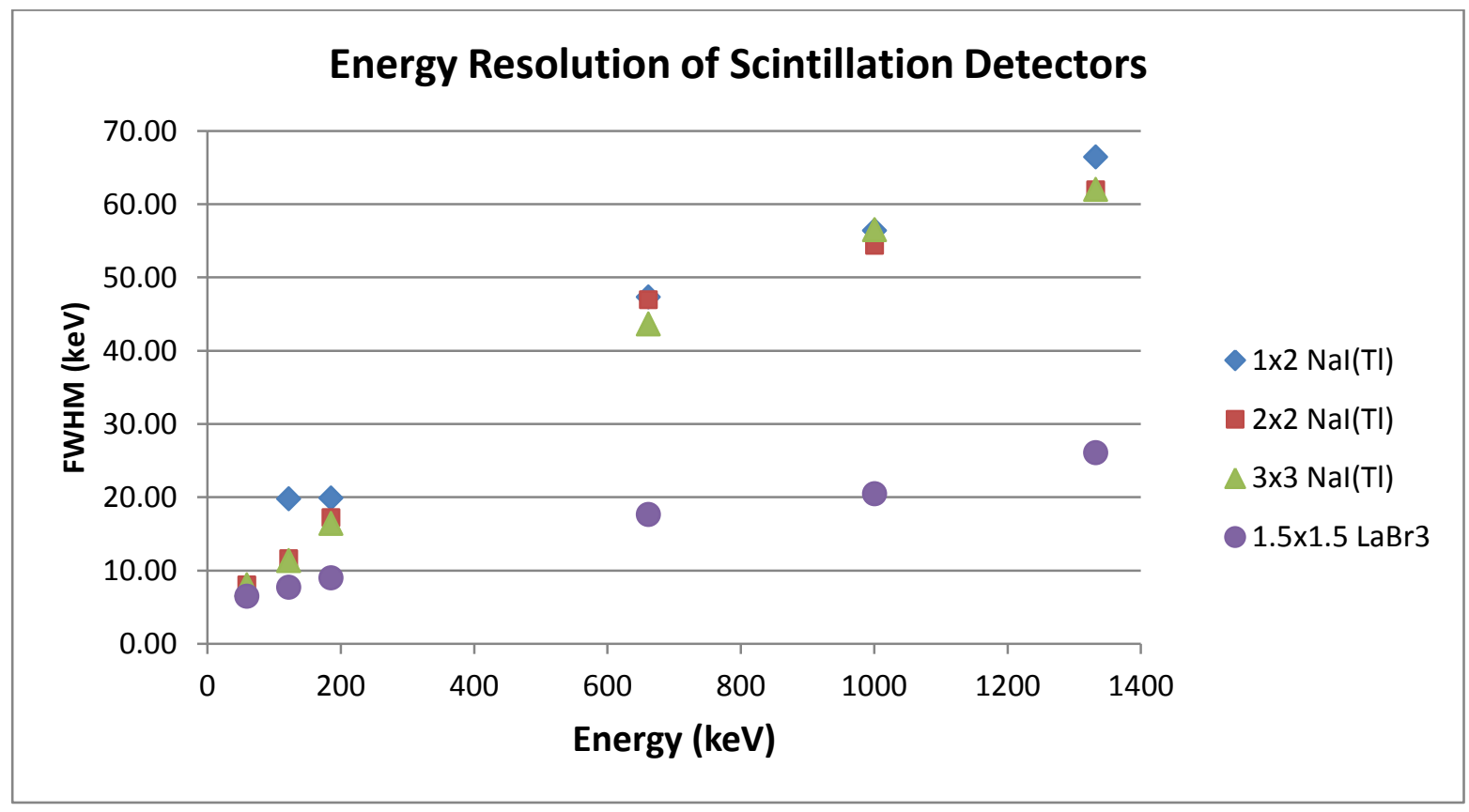

Figure 3. FWHM results for evaluated scintillation detectors.

The data illustrated in Figure 3 shows that the energy resolution of the $\mathrm{NaI}(\mathrm{Tl})$ crystals, although different sizes, are close to each other. It is worth noting that, in the FWHM results for the $1 \times 2$ in. NaI(Tl), the energy resolution at $122.1 \mathrm{keV}$ from ${ }^{57} \mathrm{Co}$ is poor when compared to other $\mathrm{NaI}(\mathrm{Tl})$ detectors. A possible reason for this degraded energy resolution at $122.1 \mathrm{keV}$ is interference from the $125.3 \mathrm{keV}$ gamma ray emitted by the ${ }^{241} \mathrm{Am}$ source attached to the $1 \times 2 \mathrm{in}$. $\mathrm{NaI}(\mathrm{Tl})$ detector. The yield of the $125.3 \mathrm{keV}$ gamma is $0.408 \%$, a small fraction when compared to the yield of the $60 \mathrm{keV}$ gamma, which is $35.9 \%$. However, based on the count rate at $60 \mathrm{keV}(1,860$ counts per second), the count rate at $125.3 \mathrm{keV}$ is estimated to be 7.6 counts per second, which is not insignificant.

The energy resolution of $\mathrm{LaBr}_{3}(\mathrm{Ce})$ at energies in the vicinity of $1,001 \mathrm{keV}$ is better by a factor of $2-3$ when compared to $\mathrm{NaI}(\mathrm{Tl})$ detectors. This is not surprising since the scintillation light output of $\mathrm{LaBr}_{3}(\mathrm{Ce})$ has a strong linear response to the photon energy. 


\subsubsection{Peak Count Rates}

The peak count rates registered at various gamma ray energies in the 59.6-1332.5 keV energy range are presented in Figure 4. The data points in the energy range between $59.6 \mathrm{keV}$ and $1332 \mathrm{keV}$ are useful in mapping out the unattenuated efficiency profile of the various detectors across the energy range of interest. Since the measurements were performed at exactly the same source-to-detector distance, the net peak count rates registered by the different detectors can be inter-compared, and conclusions can be drawn regarding the relative full energy peak efficiency of the detectors.

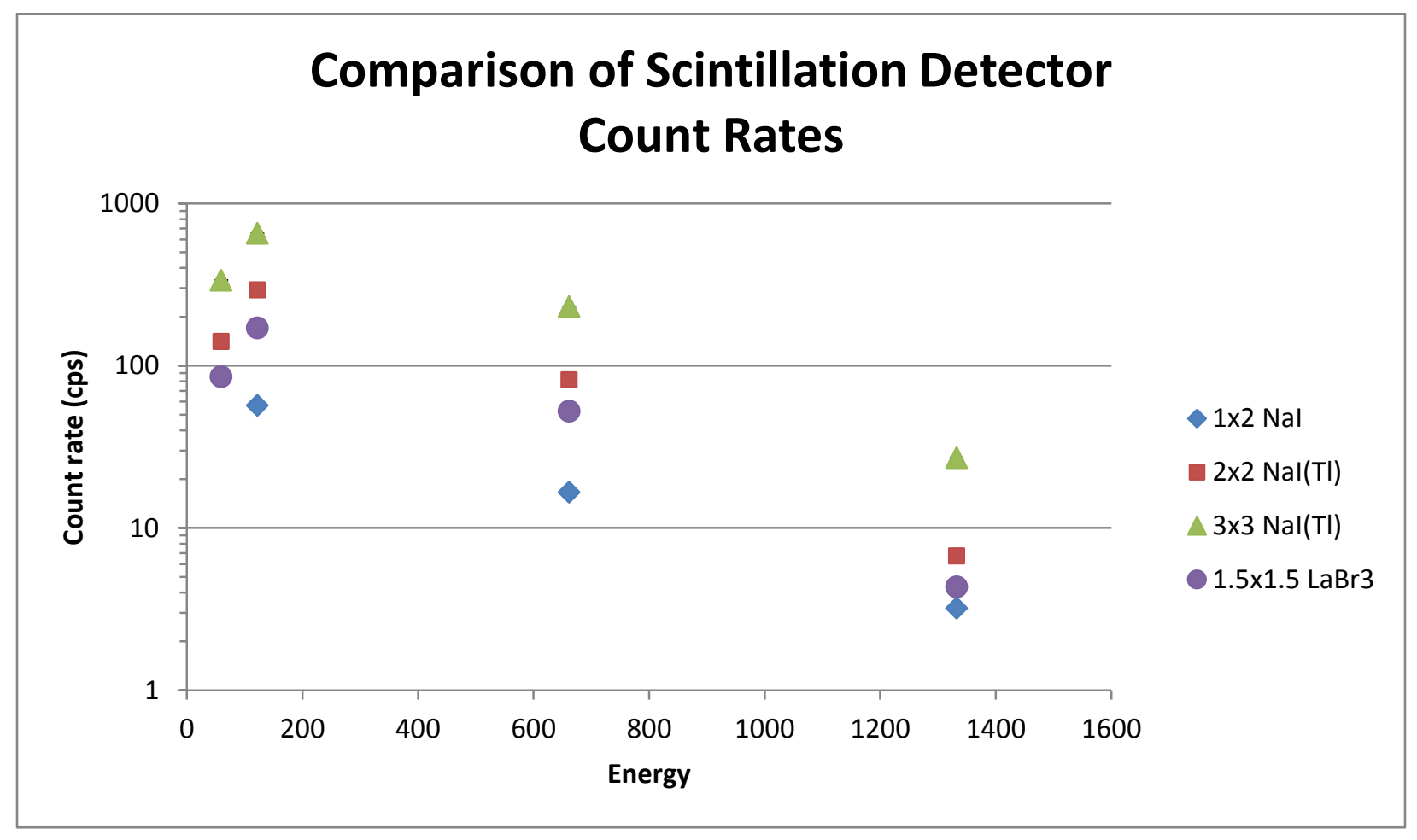

Figure 4. Comparison of scintillation detector count rates.

The trends seen in Figure 4 are as expected; the $3 \times 3$ in. $\mathrm{NaI}(\mathrm{Tl})$ detector has the highest efficiency overall, while the $1 \times 2$ in. $\mathrm{NaI}(\mathrm{Tl})$ currently used in HEU hold-up campaign has the lowest efficiencies. The $1 \times 2$ in. detector has the smallest active volume amongst the scintillation detectors evaluated.

The count rates from the NBL standards at $186 \mathrm{keV}$ were plotted as a function of enrichment (atom percentage). Ideally, this must be a linear relationship because the thickness of the $\mathrm{U}_{3} \mathrm{O}_{8}$ layer is "infinitely thick" to the $186 \mathrm{keV}$ gamma rays. The results illustrated in Figure 5 show that the $3 \times 3$ in. $\mathrm{NaI}(\mathrm{Tl})$ detector registered the highest count rate compared to the other detector candidates. This is not surprising since, amongst the candidates under consideration, the $3 \times 3 \mathrm{in} . \mathrm{NaI}(\mathrm{Tl})$ detector has the highest active volume for detection. 


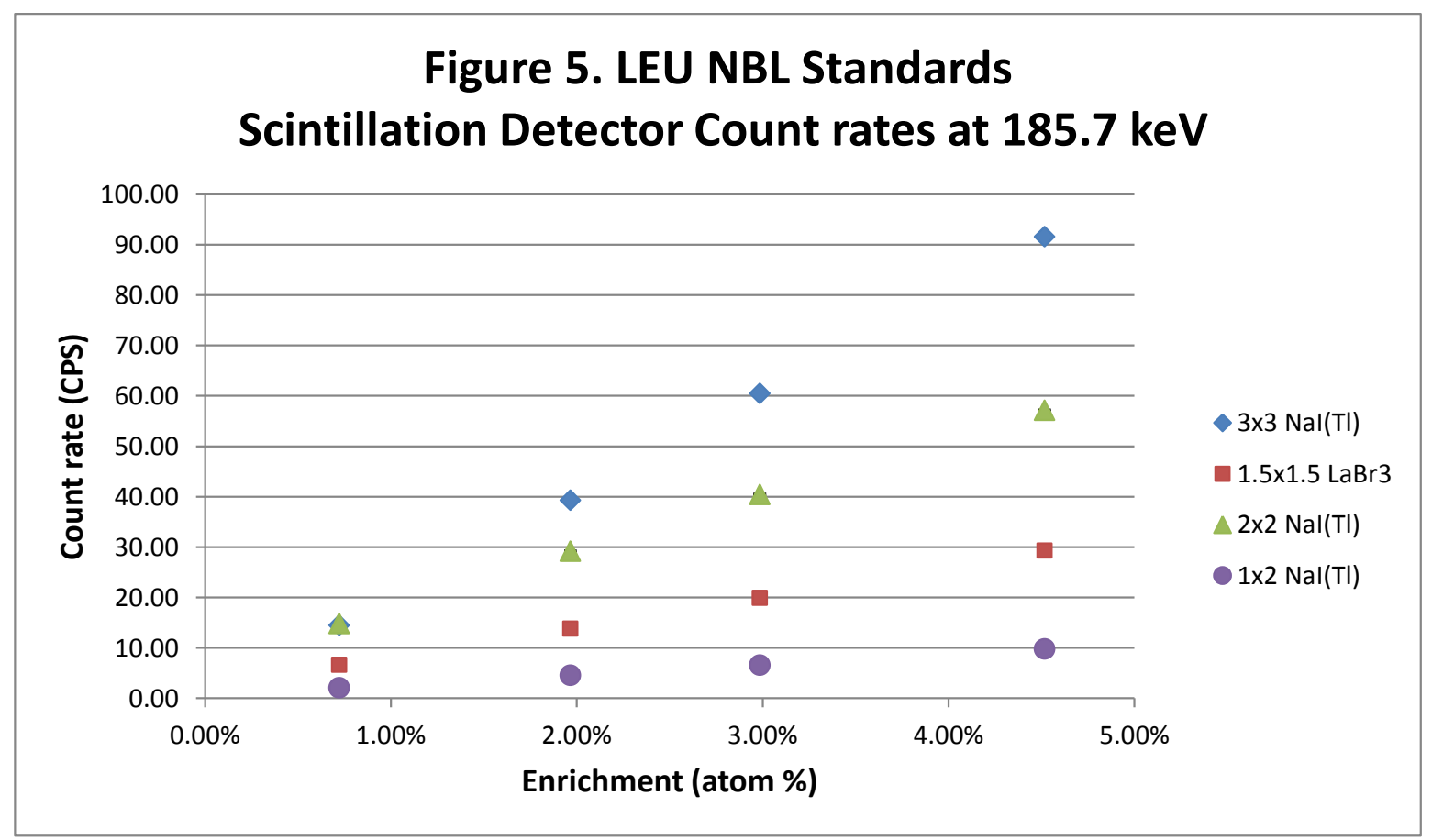

Figure 5. LEU scintillation detector count rates at $185.7 \mathrm{keV}$.

The results presented in Figure 6 highlight that the efficiency of the $3 \times 3$ in. $\mathrm{NaI}(\mathrm{Tl})$ detector for detecting the 1,001 keV gamma rays from LEU is about a factor three greater than the other scintillators evaluated. The plots show a slight decreasing trend as the enrichment increases, which is consistent with the decrease in the ${ }^{238} \mathrm{U}$ fraction.

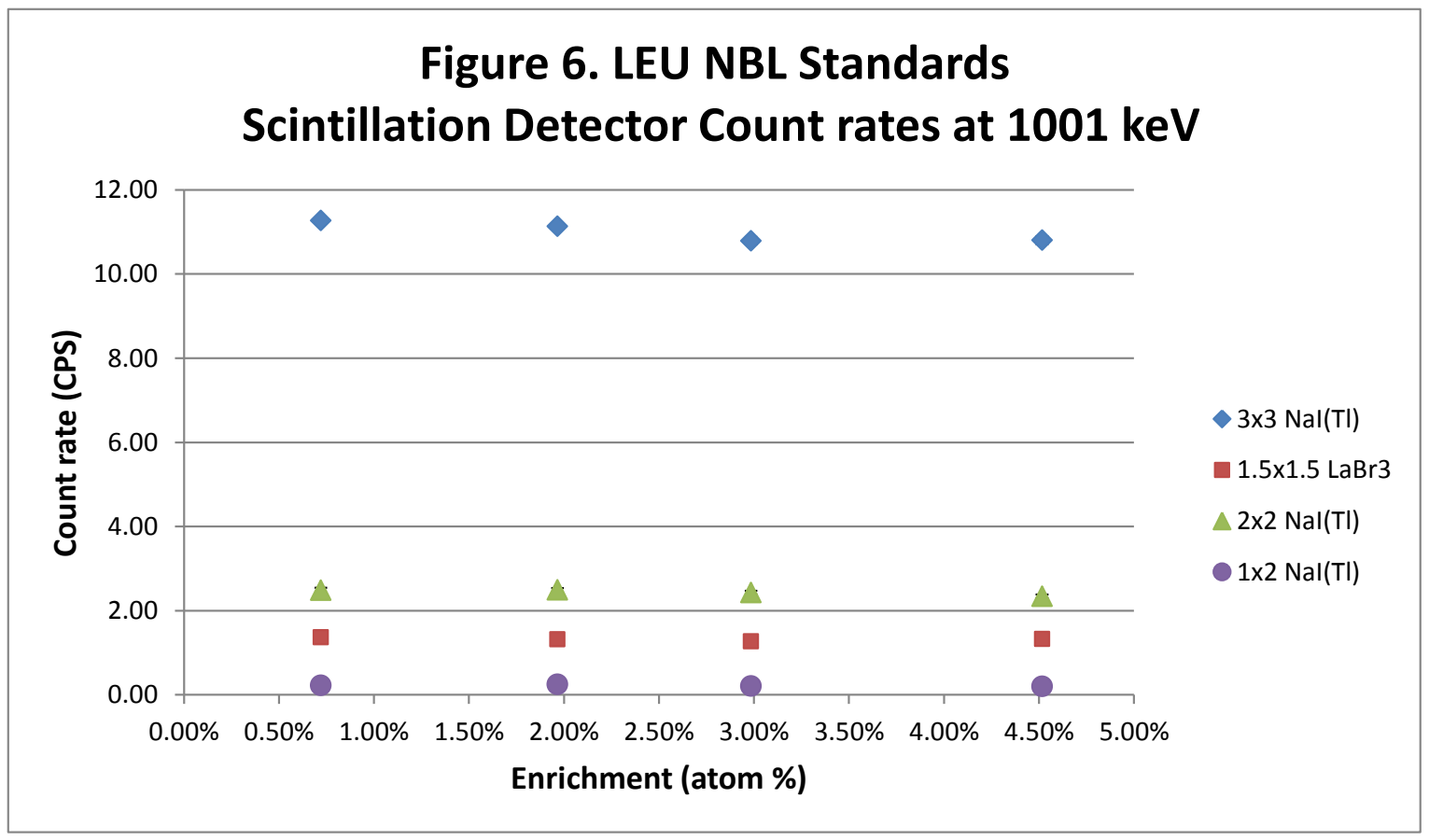

Figure 6. LEU scintillation detector count rates at $1,001 \mathrm{keV}$. 


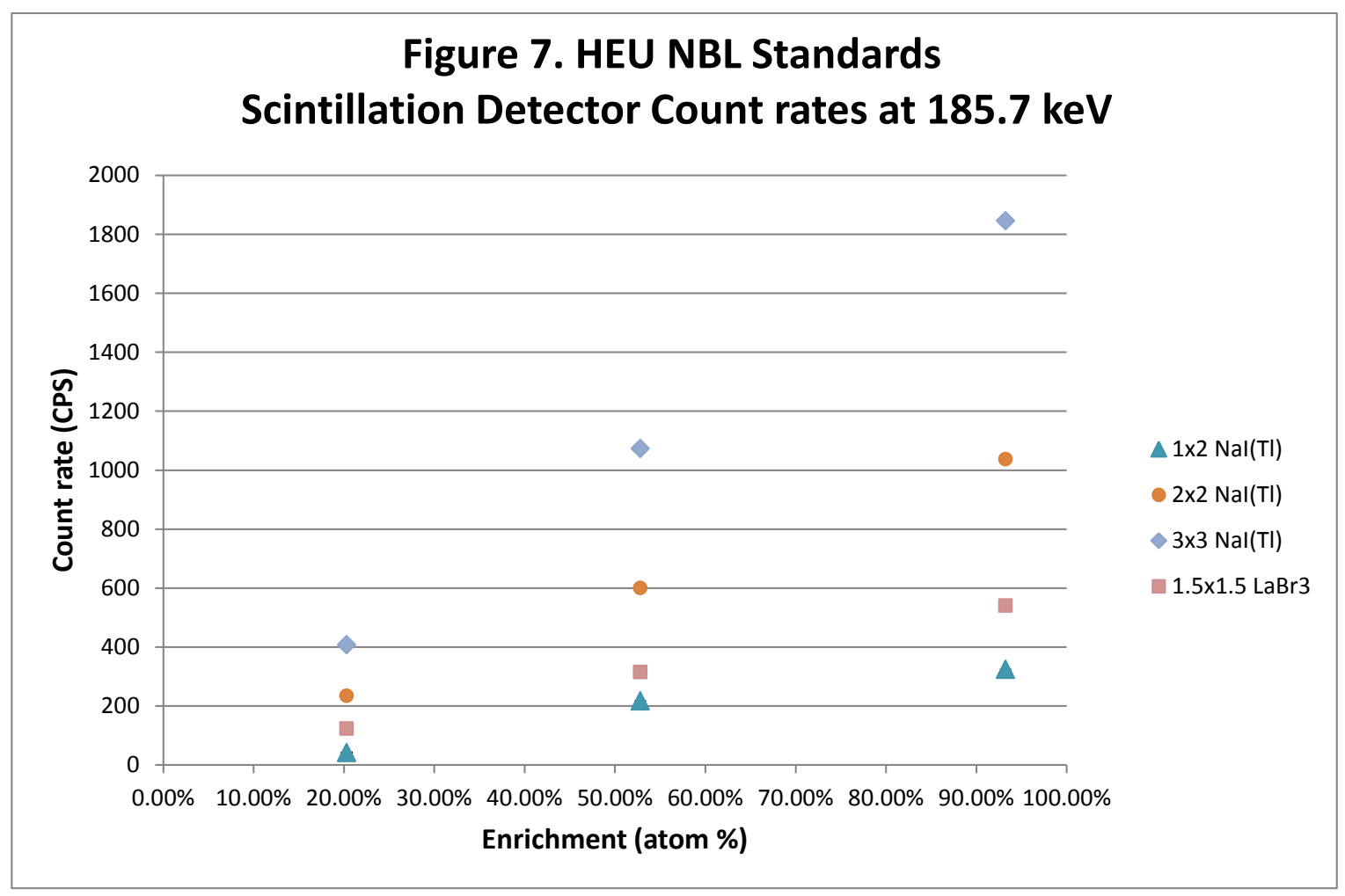

Figure 7. HEU scintillation detector count rates at $185.7 \mathrm{keV}$.

Figure 7 shows the scintillation detector count rates from the $186 \mathrm{keV}$ peak gamma ray. Besides the 1,001 $\mathrm{keV}$ gamma ray, ${ }^{234 \mathrm{~m}} \mathrm{~Pa}$ also emits a gamma ray at $766 \mathrm{keV}$, albeit with a much lower yield. The 1,001 $\mathrm{keV}$ gamma ray has a yield of $0.84 \%$, whereas the $766 \mathrm{keV}$ gamma ray has a yield of $0.23 \%$. The count rate registered in the $766 \mathrm{keV}$ gamma peak is about a factor five smaller than the $1,001 \mathrm{keV}$ peak area. There is no advantage to using the $766 \mathrm{keV}$ gamma line unless one is interested in isotopic analysis.

The measured count rate, and the uncertainty in the measured count rate at a given gamma ray peak from a uranium isotope, depends on a number of competing factors, listed below.

1. Uranium enrichment. The greater the uranium enrichment, the higher the count rate from the 186 $\mathrm{keV}$ gamma and the smaller the uncertainty. At low enrichments, the ${ }^{238} \mathrm{U}$ content is higher, and the count rate at the $1,001 \mathrm{keV}$ tends to increase.

2. Deposit thickness. With higher deposit thickness, self-attenuation becomes greater. Self-attenuation will be more severe for the $186 \mathrm{keV}$ gamma than for the 1,001 keV gamma (as shown in Figures 1215). Self-attenuation is discussed in greater detail in Section 3.2.

3. Gamma ray yield. The yield of the $1,001 \mathrm{keV}$ gamma is $0.845 \%$, a value much smaller than the $57.0 \%$ yield of the $186 \mathrm{keV}$ gamma.

4. Detector efficiency. A detector with a greater intrinsic efficiency would register a higher signal rate-provided the background interference is mitigated using appropriate shielding. One should be mindful that a detector that is efficient in registering signal from the source is also efficient in registering background. 
5. Attenuation through pipe wall or other absorbers. The $186 \mathrm{keV}$ gamma will suffer more attenuation than the $1,001 \mathrm{keV}$ gamma.

6. Background interference. It is more difficult to shield the background from the $1,001 \mathrm{keV}$ gamma ray because of its higher penetrating ability relative to the $186 \mathrm{keV}$ gamma. Shielding effects and detection limits are discussed in Section 3.3 of this report.

\subsubsection{Peak-to-Continuum Ratios for Scintillation Detectors}

The peak-to-continuum ratio is a powerful metric for detector sensitivity at a given photon energy and at a given uranium enrichment. The greater the peak-to-continuum ratio, the higher the detector's sensitivity to the gamma ray of interest. The peak-to-continuum ratios at the gamma energies of $186 \mathrm{keV}$ and 1,001 $\mathrm{keV}$ were studied for the scintillation detectors. The results are shown in Figures 8-11.

The $3 \times 3$ in. $\mathrm{NaI}(\mathrm{Tl})$, the $2 \times 2$ in. $\mathrm{NaI}(\mathrm{Tl})$, and the $1.5 \times 1.5$ in. $\mathrm{LaBr}_{3}(\mathrm{Ce})$ detectors were unshielded, whereas the $1 \times 2$ in. $\mathrm{NaI}(\mathrm{Tl})$ was a shielded probe.

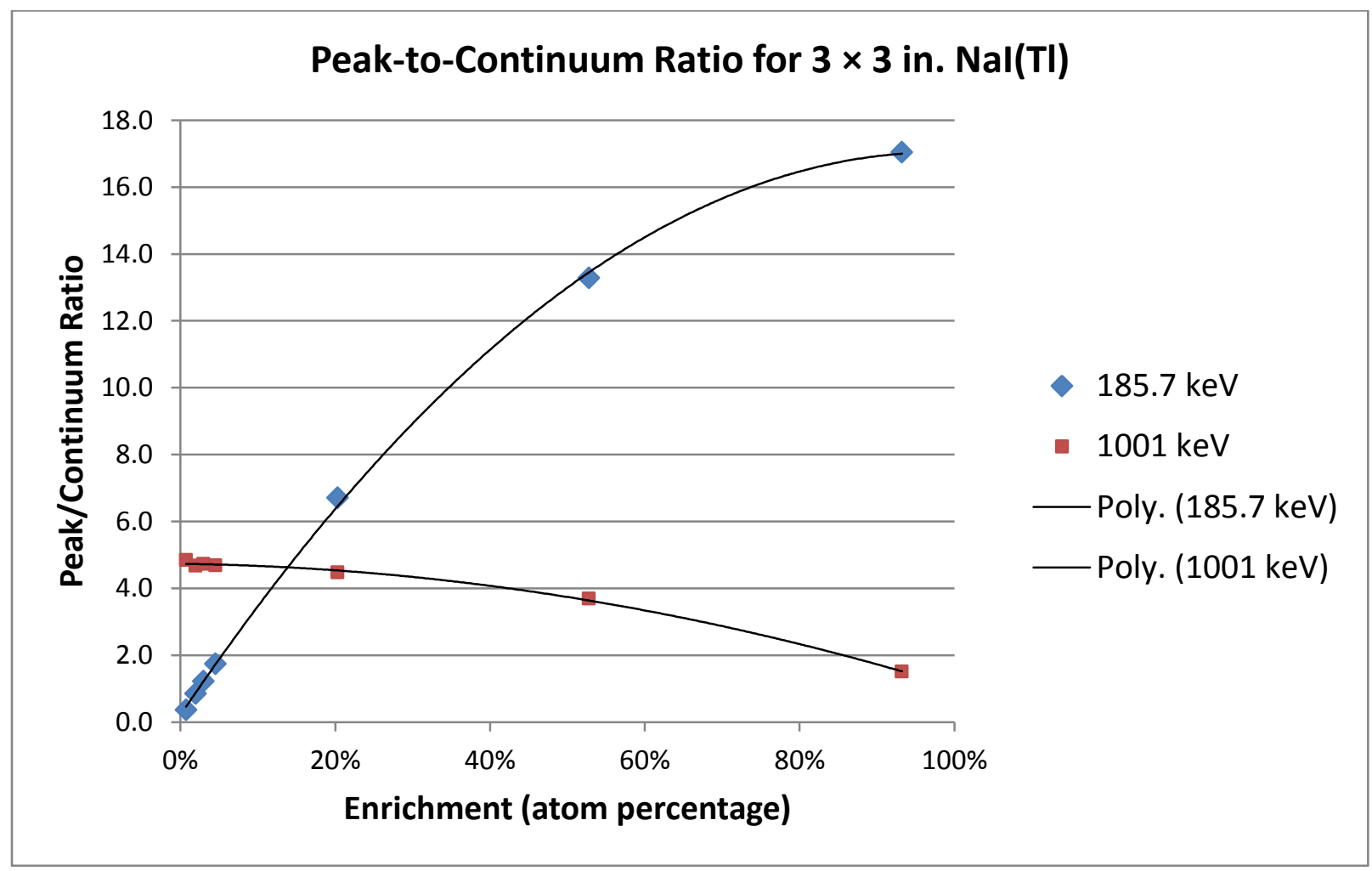

Figure 8. Peak-to-continuum ratio for $3 \times 3$ in. $\mathrm{NaI}(\mathrm{Tl})$ 


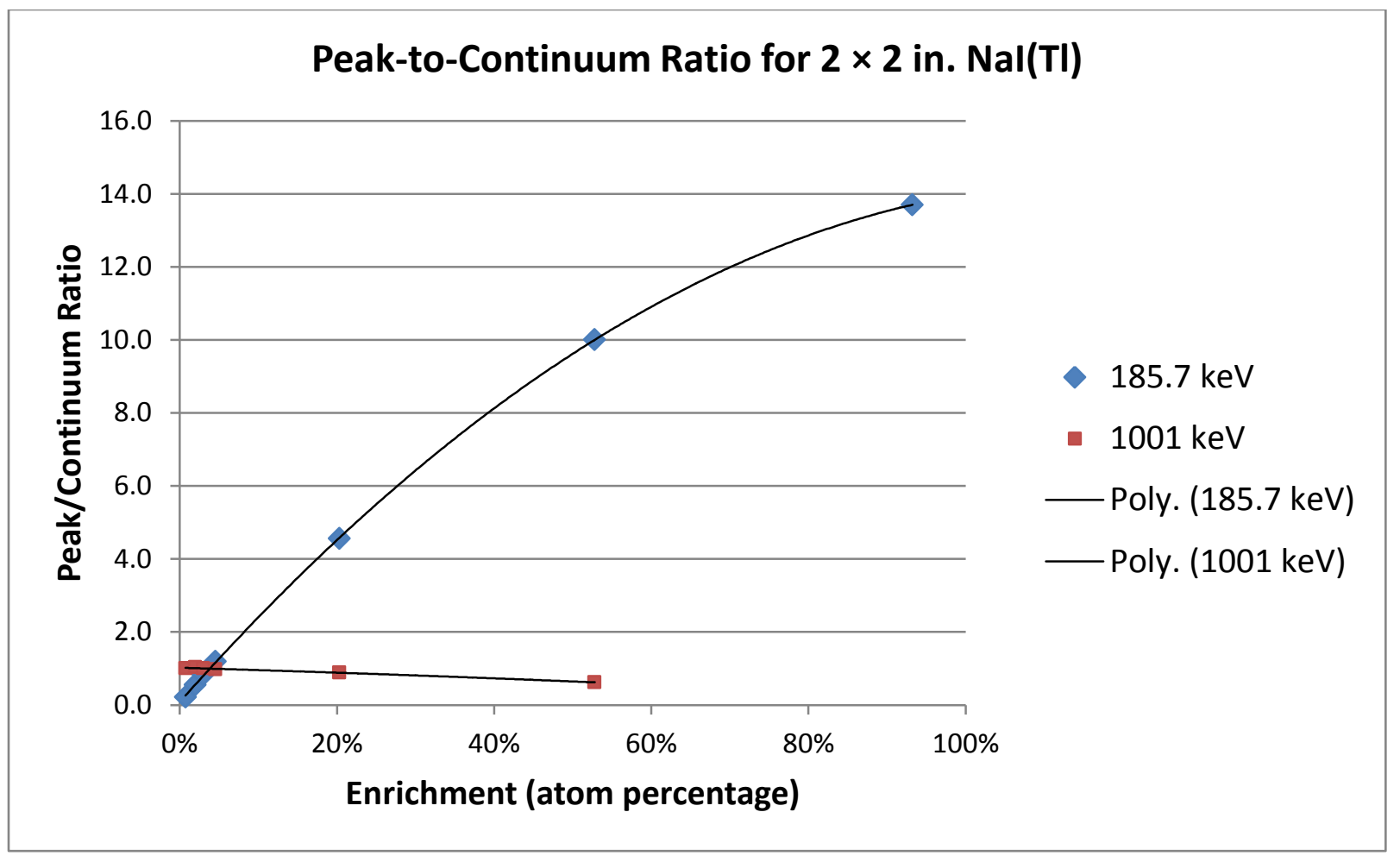

Figure 9. Peak-to-continuum ratio for $2 \times 2 \mathrm{in}$. $\mathrm{NaI}(\mathrm{Tl})$

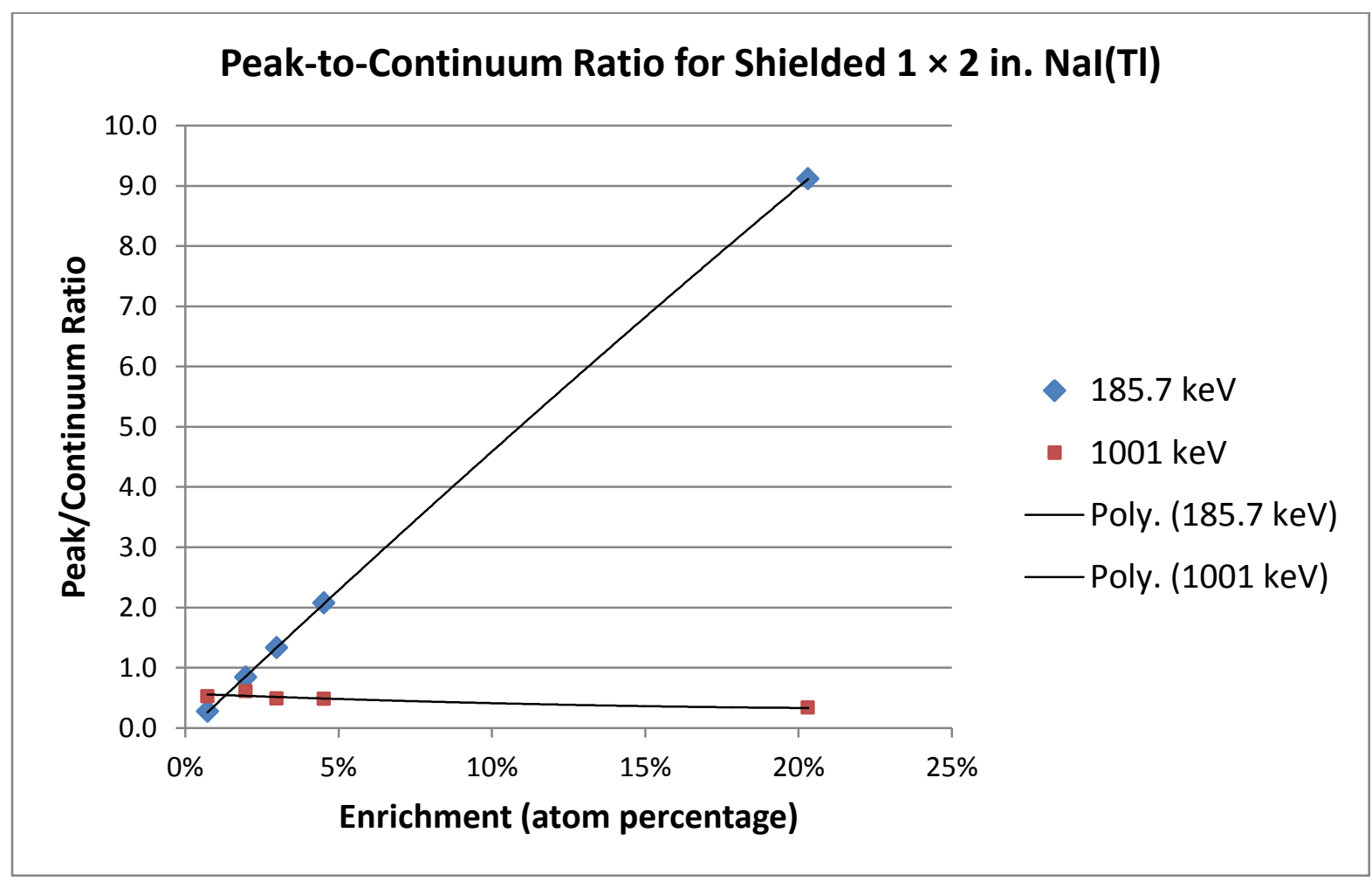

Figure 10. Peak-to-continuum ratio for shielded $1 \times 2$ in. $\mathrm{NaI}(\mathrm{Tl})$ 


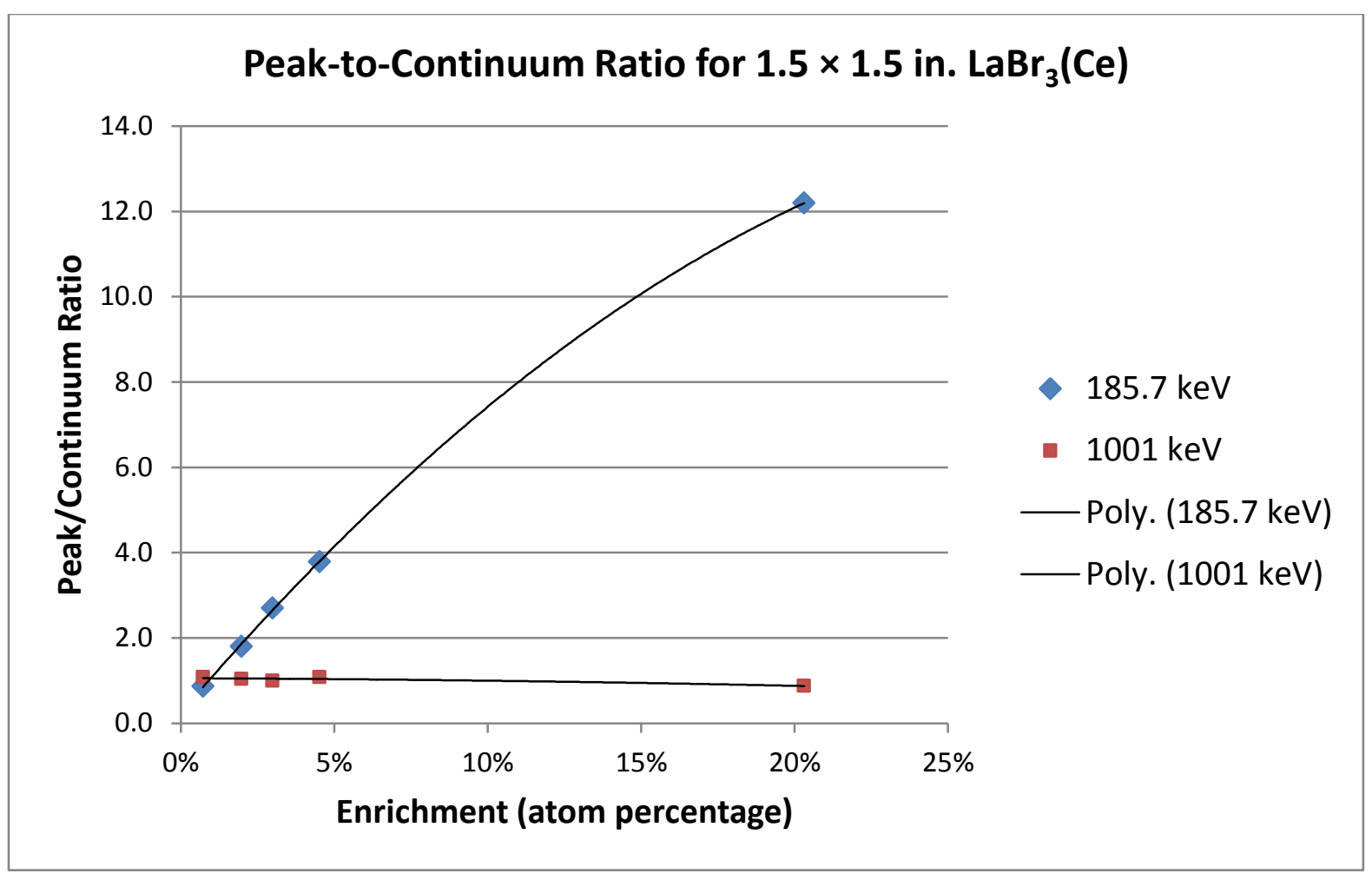

Figure 11. Peak-to-continuum ratio for $1.5 \times 1.5 \mathrm{in} . \mathrm{LaBr}_{3}(\mathrm{Ce})$.

Deposits that are "infinitely thick" for the $186 \mathrm{keV}$ gamma rays can be measured and analyzed using the $1,001 \mathrm{keV}$ gamma ray emitted by ${ }^{234 \mathrm{~m}} \mathrm{~Pa}$ (daughter of ${ }^{238} \mathrm{U}$ ). The material being measured at Portsmouth is aged, and therefore it is valid to assume a secular equilibrium between ${ }^{238} \mathrm{U},{ }^{234} \mathrm{Th}$, and ${ }^{234 \mathrm{~m}} \mathrm{~Pa}$.

For example, for $\mathrm{UO}_{2}$ powder with a density of $3.0 \mathrm{~g} / \mathrm{cm}^{3}$, the mean free path (MFP) for $186 \mathrm{keV}$ photons is $0.26 \mathrm{~cm}$, whereas, for $1,001 \mathrm{keV}$ photons, the MFP is $4.52 \mathrm{~cm}$. Other highlights from the experiments include:

- For LEU, amongst the detector candidates that were considered, the $3 \times 3$ in. $\mathrm{NaI}(\mathrm{Tl})$ detector shows the highest peak-to-continuum ratio at $1,001 \mathrm{keV}$. The efficiency of the $3 \times 3 \mathrm{in}$. NaI(Tl) detector for detecting the $1,001 \mathrm{keV}$ gamma rays is higher than any of the other candidates. Therefore, it is highly suitable for measuring the $1,001 \mathrm{keV}$ gamma ray.

- In the case of the $\mathrm{LaBr}_{3}(\mathrm{Ce})$ detector, the peak-to-continuum ratio at $1,001 \mathrm{keV}$ is comparable to that of the $2 \times 2$ in. $\mathrm{NaI}(\mathrm{Tl})$ detector. Even though the $\mathrm{LaBr}_{3}(\mathrm{Ce})$ has a superior energy resolution, the peak-to-continuum ratio is not better than that of a $2 \times 2 \mathrm{in}$. $\mathrm{NaI}(\mathrm{Tl})$ detector because of the elevated continuum from the intrinsic background, as discussed previously. No amount of external shielding would mitigate this problem.

- $\quad$ The shielded $1 \times 2$ in. $\mathrm{NaI}(\mathrm{Tl})$ probe has a high sensitivity for the $186 \mathrm{keV}$ gamma ray above enrichments of approximately $3 \%$. For deposits that are not "infinitely thick" for the $186 \mathrm{keV}$ gamma rays, the $1 \times 2$ in. $\mathrm{NaI}(\mathrm{Tl})$ shielded probe can also be useful for ${ }^{235} \mathrm{U}$ enrichments above $2 \%$. 
The selection of the best detector for LEU hold-up will need to be made based on a number of considerations, including detection efficiency, peak/continuum ratio, gamma ray detection at a given yield, weight of the shielded probe, and the cost of the detector.

\subsection{SELF-ATTENUATION AND INFINITE THICKNESS}

The self-attenuation correction factors were estimated at various measured areal densities of $\mathrm{UO}_{2} \mathrm{~F}_{2}$, at gamma ray energies of $186 \mathrm{keV}$ and $1,001 \mathrm{keV}$. The correction factor for self-attenuation at a given gamma ray energy is determined from the ratio of the true (or corrected) areal density to the measured areal density of a slab deposit, as shown in Equation 1 (Russo et al. 2000).

$$
C F_{\text {self-attn }}=\frac{(\rho x)_{\text {true }}}{(\rho x)_{\text {meas }}}=\frac{\mu / \rho \cdot(\rho x)_{\text {true }}}{\left(1-\exp \left(-\mu / \rho \cdot(\rho x)_{\text {true }}\right)\right.}
$$

Equation (1) can be re-arranged and written in terms of true and measured areal densities, as shown in Equation 2 (Russo et al. 2000).

$$
\rho x_{\text {true }}=-\frac{1}{(\mu / \rho)} * \ln \left[1-(\mu / \rho) *(\rho x)_{\text {Meas }}\right]
$$

As the value of the product $(\mu / \rho) *(\rho x)_{\text {meas }}$ approaches 1 , the value of the true areal density approaches infinity, and the deposit becomes infinitely thick to its own gamma rays (of a given energy). Furthermore, the uncertainty in the corrected value is magnified relative to the measured uncertainty, as shown in Equation 3.

$$
\sigma_{(\rho x) \text { true }}=\frac{\sigma_{(\rho x) \text { meas }}}{\left(1-\mu / \rho \cdot(\rho x)_{\text {meas }}\right)}
$$

The true areal density is plotted as a function of measured areal densities for gamma ray energies of 186 $\mathrm{keV}$ (Figure 12) and 1,001 keV (Figure 13) in order to provide a visual representation of the infinite thickness condition. 


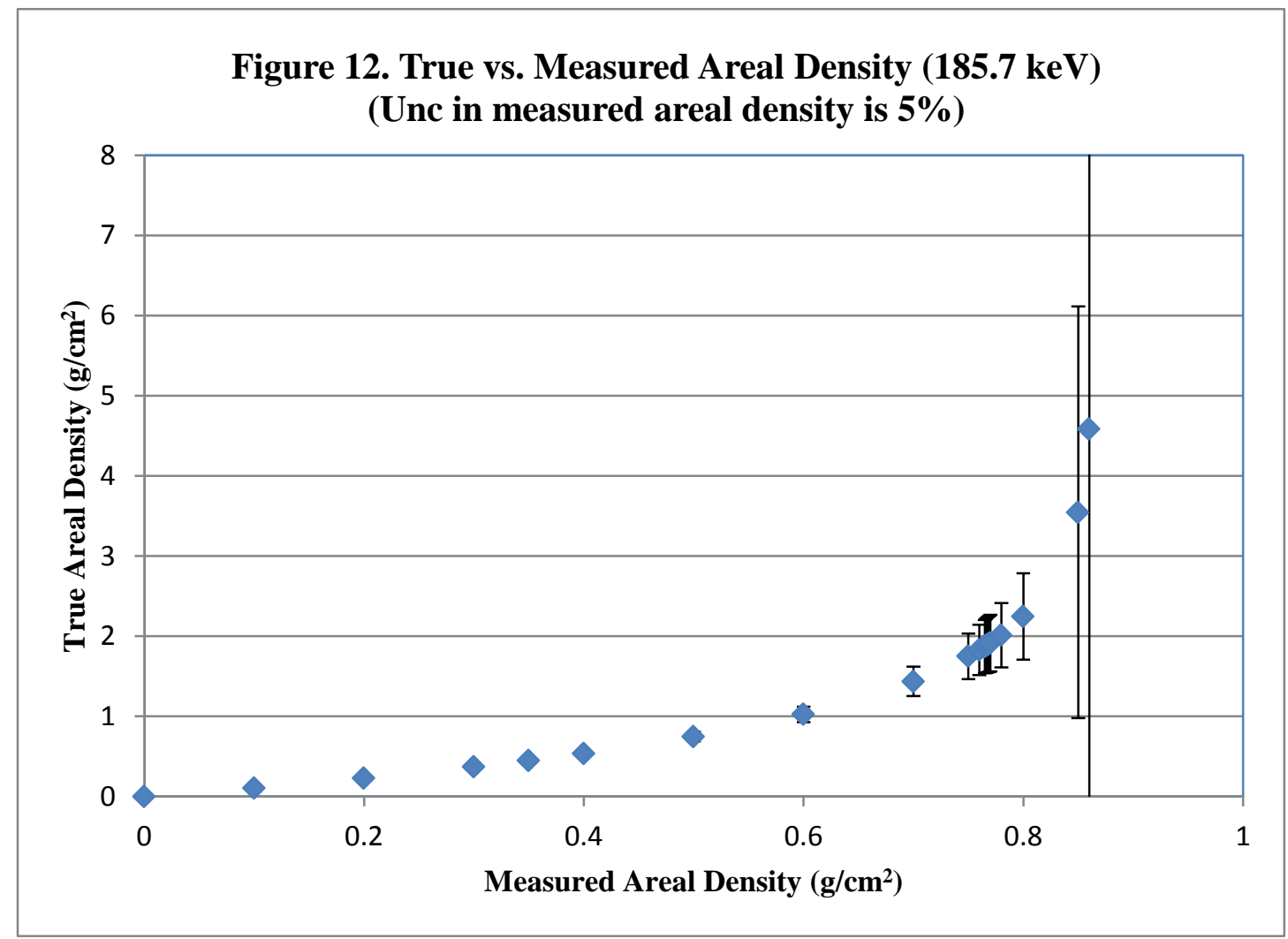

Figure 12. True vs. measured area density (185.7 keV).

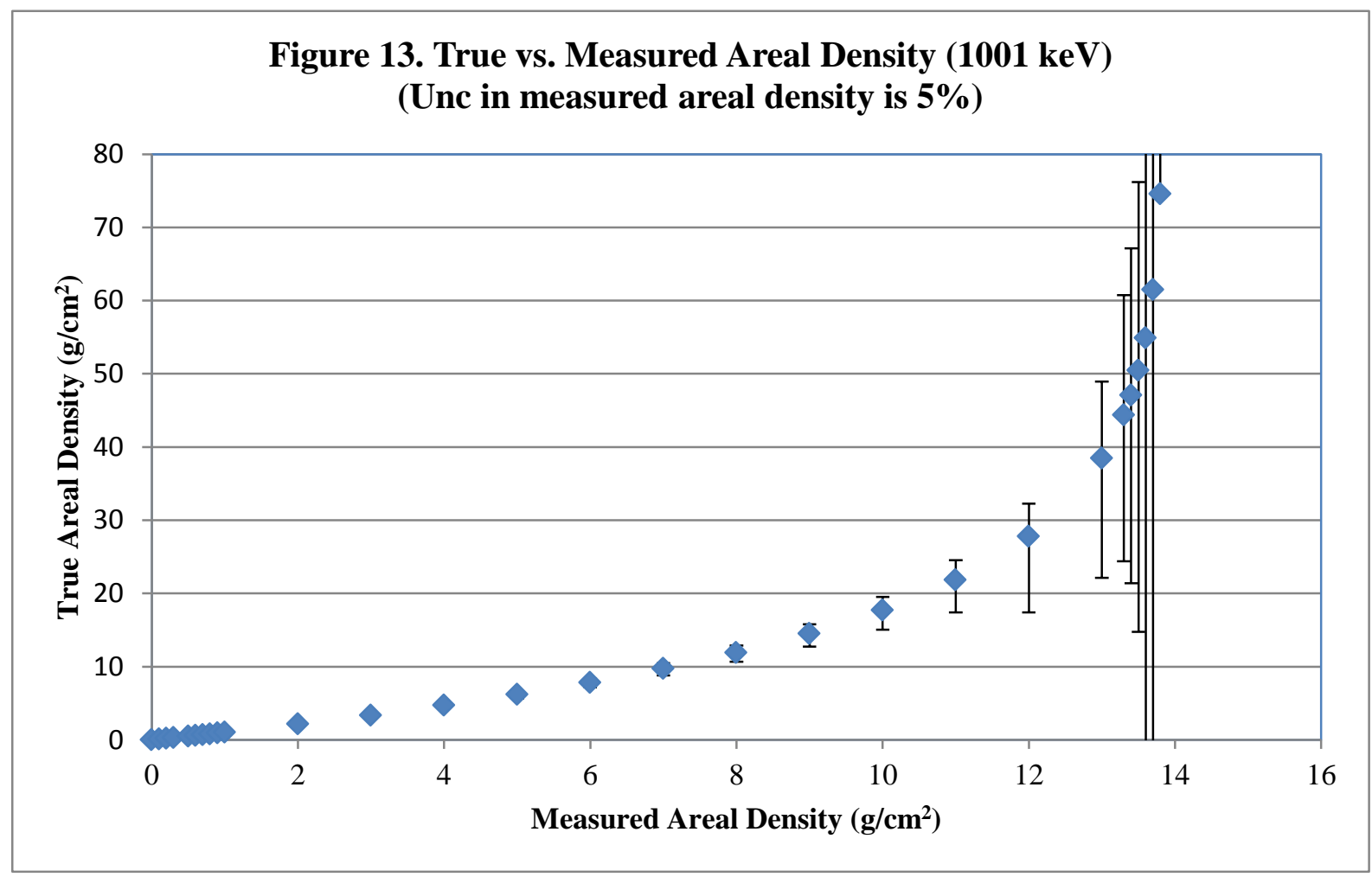

Figure 13. True vs. measured area density $(1,001 \mathrm{keV})$. 
From Figure 13, it is evident that the infinite thickness condition is reached for the $186 \mathrm{keV}$ gamma ray energy at a true areal density of just under $5 \mathrm{~g} / \mathrm{cm}^{2}$. As the true areal density approaches a value close to 5 $\mathrm{g} / \mathrm{cm}^{2}$, its uncertainty balloons to a very large value. For example, the areal density of the $\mathrm{U}_{3} \mathrm{O}_{8}$ layer in the NBL standards is $5.2 \mathrm{~g} / \mathrm{cm}^{2}$, and it is therefore infinitely thick to the $186 \mathrm{keV}$ gamma rays, but not to the $1,001 \mathrm{keV}$ gamma rays. For the $1,001 \mathrm{keV}$ gamma, the infinite thickness condition is reached at a much higher true areal density of approximately $75 \mathrm{~g} / \mathrm{cm}^{2}$.

The calculations for the results shown in Figures Figure 12 and Figure 13 were performed assuming an uncertainty of $5 \%$ in the measured areal densities. This assumption was made so that the infinite thickness conditions can be visualized. However, for plant-wide measurement conditions, the uncertainties could be larger since the counting time is short. The $1,001 \mathrm{keV}$ gamma ray has a higher penetration compared to the $186 \mathrm{keV}$ gamma ray; however, its yield is $0.845 \%$, which is 67 times smaller than the yield of the $186 \mathrm{keV}$ gamma ray.

Below, the self-attenuation correction factors at gamma energies of $186 \mathrm{keV}$ (Figure 14) and 1,001 keV (Figure 15) - as a function of the true areal density (equation 1) - are illustrated. The uncertainties in the self-attenuation correction become very large as the infinite thickness condition is approached.

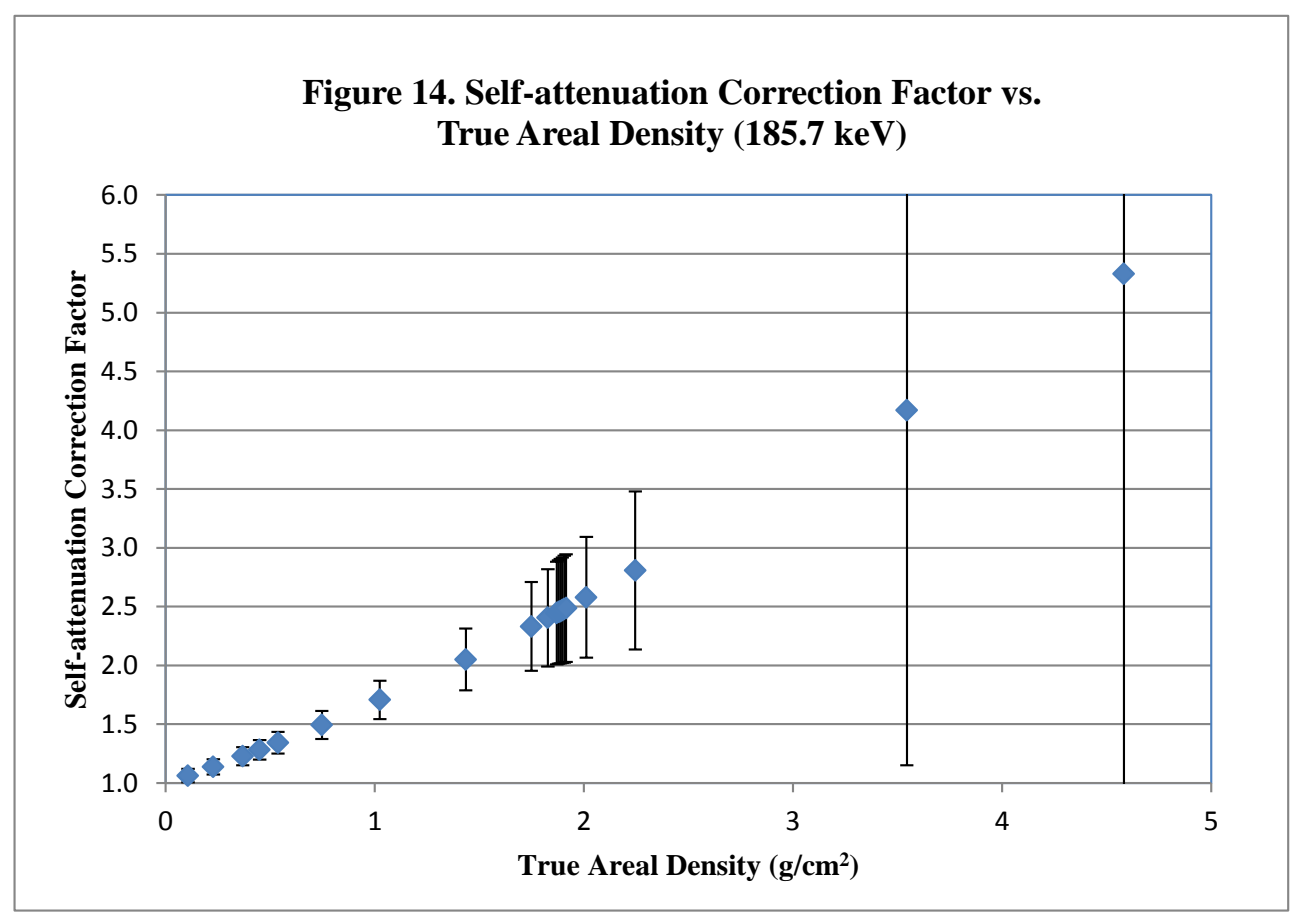

Figure 14. Self-attenuation correction factor vs. true area density (185.7 keV). 


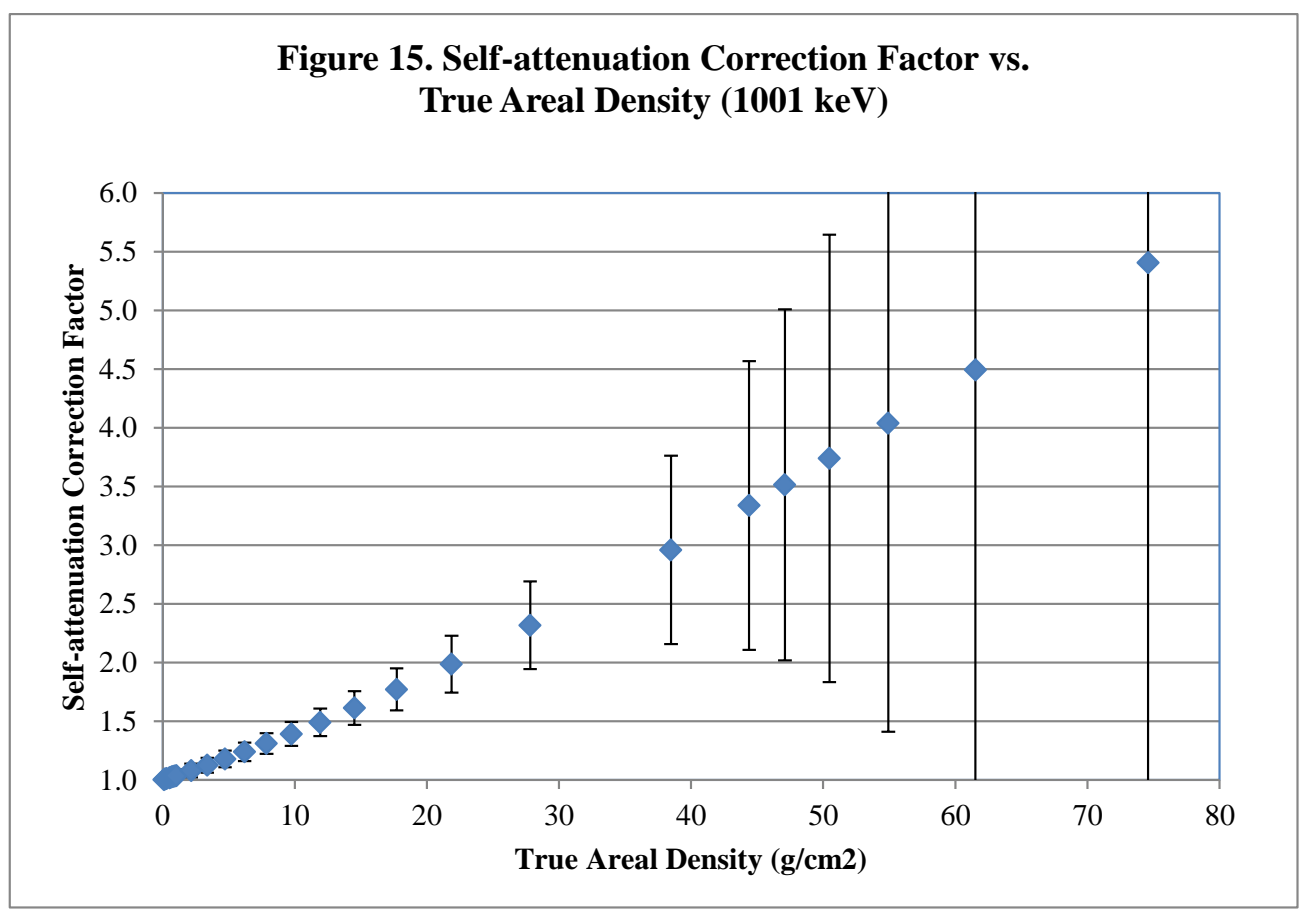

Figure 15. Self-attenuation correction factor vs. true area density $(1,001 \mathrm{keV})$.

The self-attenuation correction factor, along with its uncertainty, can be used to transition from an analysis based on $186 \mathrm{keV}$ to $1001 \mathrm{keV}$ using criterion that fixes a maximum value for the self-attenuation correction factor and its uncertainty. For example, if the maximum value for the self-attenuation correction factor is fixed at 1.30, then one can rely on the $186 \mathrm{keV}$ based analysis up to an areal density of $0.44 \mathrm{~g} / \mathrm{cm}^{2}$. For a $\mathrm{UO}_{2} \mathrm{~F}_{2}$ deposit of volumetric density 2.0 $\mathrm{g} / \mathrm{cm}^{3}$, an areal density of $0.44 \mathrm{~g} / \mathrm{cm}^{2}$ corresponds to a deposit thickness of $0.22 \mathrm{~cm}$. If the selfattenuation correction factor, estimated based on the $186 \mathrm{keV}$ data, exceeds 1.30, then one can use the analysis results from the $1,001 \mathrm{keV}$ gamma ray. For the $1,001 \mathrm{keV}$ gamma ray, a selfattenuation correction factor of 1.30 corresponds to an areal density of $7.86 \mathrm{~g} / \mathrm{cm}^{2}$ or a deposit thickness of $3.93 \mathrm{~cm}$.

\subsection{DETECTION LIMTS AND IMPACT OF SHIELDING}

The detection limits (or the minimum detectable activity [MDA] or quantity) is another parameter that is useful for comparing the performance of various detectors. The MDA for ${ }^{235} \mathrm{U}$ was determined for the various detector candidates using the Currie approach, as shown in Equation (4) (Currie 1968).

$$
M D A=\frac{2.71+3.29 * \sqrt{2 B \dot{*}}}{T * \varepsilon * \Gamma * S_{a c t}}
$$

In Equation (4) the units of MDA are grams. The MDA was estimated at $95 \%$ confidence level. The quantity $\mathrm{T}$ is the sample counting time (30 seconds), Bis the background count rate at the region of interest (ROI), $\varepsilon$ is the full energy peak efficiency of the detector for a representative deposit at a distance of $40 \mathrm{~cm}$ from the detector, $\Gamma$ is the gamma ray yield, and $\mathrm{S}_{\text {act }}$ is the specific activity of ${ }^{235} \mathrm{U}$ or ${ }^{238} \mathrm{U}$, whichever the case may be. 
The $\mathrm{U}_{3} \mathrm{O}_{8}$ layer in the CRM standards is infinitely thick to the $186 \mathrm{keV}$ gamma rays. So, an efficiency value that corresponds to the geometry of the CRM standard would not be appropriate for estimating the MDA. A representative areal density for a deposit was selected based on a "maximum acceptable selfattenuation correction (SAC) factor," e.g., 1.30. For the $186 \mathrm{keV}$ gamma, an SAC of 1.30 corresponds to an areal density of $0.44 \mathrm{gm} / \mathrm{cm}^{2}$. The $\mathrm{SAC}$ for the $\mathrm{U}_{3} \mathrm{O}_{8}$ layer in the NBL standard is 6.033 , which corresponds to an areal density of $5.2 \mathrm{~g} / \mathrm{cm}^{2}$. The efficiency for a deposit with an SAC factor of 1.30 was derived by scaling the efficiency for the NBL standard geometry by the ratio of the SAC factors (6.033 to 1.30).

For the $1,001 \mathrm{keV}$ gamma, the $\mathrm{SAC}$ for the $\mathrm{U}_{3} \mathrm{O}_{8}$ layer in the $\mathrm{NBL}$ standard is 1.19 (corresponding to an areal density of $5.2 \mathrm{~g} / \mathrm{cm}^{2}$ ). This is close enough to the maximum acceptable SAC of 1.30. Therefore, the efficiency for the NBL standard was adopted, as is, for the MDA estimation.

The relationship between a net signal count $S$, the observed gross count $G$, and a background count $B$ can be written as seen below in Equation (5).

$$
S=G-B
$$

The background $B$ includes the continuum counts $C$ under the signal peak and any peaked background interference $I$. Equation (5) can also be rewritten as:

$$
S=G-C-I
$$

The variance in the net signal is given in Equation (6).

$$
\begin{gathered}
\sigma_{S}^{2}=\sigma_{G+}^{2} \sigma_{C}^{2}+\sigma_{I}^{2} \\
\sigma_{S}^{2}=G+\sigma_{C}^{2}+\sigma_{I}^{2} \\
\sigma_{S}^{2}=(S+C+I)+\sigma_{C}^{2}+\sigma_{I}^{2}
\end{gathered}
$$

When the true net signal is zero, the uncertainty in the zero signal is given in Equation (10).

$$
\sigma_{S}^{2}=C+I+\sigma_{C}^{2}+\sigma_{I}^{2}
$$

Or:

$$
\sigma_{0}=\sqrt{B+\sigma_{B}^{2}}
$$

In the Currie approach, the "critical limit" (the limit that the signal must exceed in order to be detected) is established based on $\sigma_{0}$ (Equation 7), assuming a Gaussian probability distribution and a given confidence level. The detection limit is established above the critical limit, making allowance for an acceptable level of false negatives (failing to detect the signal when it is actually present). Currie 1968 features a thorough discussion on the subject of detection limits and MDA.

For the analysis based on the 1,001 keV gamma, the MDA for ${ }^{235}$ Uwas derived based on an assumed representative enrichment of $2 \%$. The background count rates used in the MDA estimates were the average of several long background counts performed at the ORNL Safeguards Laboratory using each individual detector. The MDA results for the $186 \mathrm{keV}$ and the $1,001 \mathrm{keV}$ gamma are given in Tables Table 2 and Table 3. 
Table 2. Minimum detectable quantities using various detector types and sizes (186 keV)

\begin{tabular}{|c|c|c|c|c|c|c|}
\hline Detector & $\begin{array}{c}\text { Background } \\
\text { count rate } \\
\text { (CPS) } \\
\text { (unshielded) } \\
\end{array}$ & $\begin{array}{c}\text { Background count } \\
\text { rate (CPS) } \\
(0.5 \text { in. Pb shield })\end{array}$ & Efficiency & $\begin{array}{c}\text { Gamma } \\
\text { Yield } \\
(\gamma \mathrm{s} / \text { decay })\end{array}$ & $\begin{array}{c}\text { MDA }(g){ }^{235} U \\
\text { Unshielded } \\
(30 \text { sec. })\end{array}$ & $\begin{array}{c}\operatorname{MDA}(\mathrm{g}){ }^{235} \mathrm{U} \\
(0.5 \text { inch } \mathrm{Pb} \\
\text { shield) }(30 \text { sec. })\end{array}$ \\
\hline $3 \times 3$ in. $\mathrm{NaI}(\mathrm{Tl})$ & 26.06 & 2.08 & $1.212 \mathrm{E}-03$ & 0.57 & 0.37 & 0.110 \\
\hline $2 \times 2$ in. $\mathrm{NaI}(\mathrm{Tl})$ & 12.70 & 1.02 & 7.556E-04 & 0.57 & 0.42 & 0.127 \\
\hline $\begin{array}{l}1.5 \times 1.5 \text { in. } \\
\mathrm{LaBr}_{3}(\mathrm{Ce})\end{array}$ & 4.38 & 0.35 & $3.876 \mathrm{E}-04$ & 0.57 & 0.49 & 0.155 \\
\hline $1 \times 2$ in. $\mathrm{NaI}(\mathrm{Tl})$ & N/A & 0.23 & $1.292 \mathrm{E}-04$ & 0.57 & N/A & 0.391 \\
\hline
\end{tabular}

From the results shown in Table 2, it becomes clear that the MDA for the $1.5 \times 1.5 \mathrm{in}$. $\mathrm{LaBr}_{3}(\mathrm{Ce})$ detector is better (lower) than the MDA for the $1 \times 2 \mathrm{in}$. $\mathrm{NaI}(\mathrm{Tl})$, but is worse than the MDA for the $2 \times 2 \mathrm{in}$. $\mathrm{NaI}(\mathrm{Tl})$. So, for measuring the $186 \mathrm{keV}$ gamma from LEU deposits, the $2 \times 2 \mathrm{in}$. NaI(Tl) detector, rather than the $1.5 \times 1.5 \mathrm{in}$. $\mathrm{LaBr}_{3}(\mathrm{Ce})$ detector, will be suitable. In fact, it is recommended that the analysis be carried out based on both $186 \mathrm{keV}$ and 1,001 keV gammas, and a best value (e.g., weighted average of the masses) be selected for reporting.

Table 3. Minimum detectable quantities using various detector types and sizes $(1,001 \mathrm{keV})$

\begin{tabular}{|c|c|c|c|c|c|}
\hline Detector & $\begin{array}{c}\text { Background } \\
\text { count rate } \\
\text { (CPS) } \\
\text { (unshielded) }\end{array}$ & Efficiency & $\begin{array}{c}\text { Gamma } \\
\text { Yield } \\
(\gamma \text { s/decay })\end{array}$ & $\begin{array}{c}\operatorname{MDA}(\mathrm{g}){ }^{238} \mathrm{U} \\
\quad(30 \text { sec.) }\end{array}$ & $\begin{array}{c}\text { MDA (g) }{ }^{235} \mathbf{U} \\
\quad \text { (30 sec.) }\end{array}$ \\
\hline $3 \times 3$ in. $\mathrm{NaI}(\mathrm{Tl})$ & 2.10 & $5.826 \mathrm{E}-04$ & 0.00842 & 22.04 & 0.45 \\
\hline $2 \times 2$ in. $\mathrm{NaI}(\mathrm{Tl})$ & 1.28 & $1.405 \mathrm{E}-04$ & 0.00842 & 72.89 & 1.49 \\
\hline $1.5 \times 1.5$ in. $\mathrm{LaBr}_{3}(\mathrm{Ce})$ & 1.09 & 7.962E-05 & 0.00842 & 119.39 & 2.44 \\
\hline $1 \times 2$ in. $\mathrm{NaI}(\mathrm{Tl})$ & 0.11 & $1.224 \mathrm{E}-05$ & 0.00842 & 293.26 & 5.98 \\
\hline$* 2 \times 3$ in. $\mathrm{NaI}(\mathrm{Tl})$ & $* 1.43$ & $* 2.589 \mathrm{E}-04$ & 0.00842 & 41.50 & 0.85 \\
\hline
\end{tabular}

As shown in Table 3, of the various detector candidates evaluated, the $3 \times 3 \mathrm{in}$. NaI(Tl) gives the lowest MDA value for ${ }^{238} U$ (and correspondingly for ${ }^{235} U$ for a given enrichment). The MDA was also calculated for an additional detector candidate - a $2 \times 3$ in. $\mathrm{NaI}(\mathrm{Tl})$ detector - to evaluate if this detector size would help mitigate the weight of the shielding while still providing a relatively low MDA for ${ }^{238} \mathrm{U}$. The background count rate for the $2 \times 3 \mathrm{in}$. $\mathrm{NaI}(\mathrm{Tl})$ detector was taken as the average of the count rates from the $3 \times 3$ in. and $2 \times 2$ in. detectors, weighted by their active volumes. The efficiency of the $2 \times 3$ in. $\mathrm{NaI}(\mathrm{Tl})$ detector was estimated based on the active volume ratio with respect to the $3 \times 3 \mathrm{in}$. detector.

At the locations where the LEU campaign will be conducted, one can expect significant interference from the $1,001 \mathrm{keV}$ gamma rays present in the background. It is important to shield and collimate the detector in these conditions. The higher energy and penetration potential of the $1,001 \mathrm{keV}$ photons makes it challenging to shield the detector from them. The MFP of a $186 \mathrm{keV}$ gamma ray in lead is $0.0785 \mathrm{~cm}$. The MFP of a $1,001 \mathrm{keV}$ gamma ray in lead is $1.298 \mathrm{~cm}-16.5$ times higher than that of $186 \mathrm{keV}$ gamma rays. Consequently, the shielding requirements for a scintillation probe used in LEU measurements will be different.

Increasing the thickness of the lead shielding decreases the background continuum but also increases the overall weight of the probe. The impact of shielding was studied via measurements of the natural uranium

\footnotetext{
* The results for the $2 \times 3$ in. $\mathrm{NaI}(\mathrm{Tl})$ detector are estimated values based on $3 \times 3$ in. and $2 \times 2$ in. NaI.
} 
standard placed to the side of the detector with and without a 0.5 in. thick lead shadow shield in front of the source. With the $0.5 \mathrm{in}$. lead shielding, a transmission factor of 0.39 was obtained for the $1,001 \mathrm{keV}$ gamma rays. Based on this measurement, the MDA of ${ }^{238} U$ (and ${ }^{235} U$ ) was determined using the three $\mathrm{NaI}(\mathrm{Tl})$ detectors with various shielding configurations. The results are presented in Table 4.

Table 4. Impact of shielding on MDA and the weight of the probe

\begin{tabular}{|c|c|c|c|c|c|}
\hline Detector & $\begin{array}{l}\text { Pb Shield } \\
\text { Thickness } \\
\text { (in.) }\end{array}$ & $\begin{array}{c}\text { Transmission } \\
\text { factor }(1,001 \mathrm{keV})\end{array}$ & $\begin{array}{c}\text { MDA } \\
\left(\mathrm{g}^{238} \mathrm{U}\right)(30 \text { sec. })\end{array}$ & $\begin{array}{c}\text { MDA } \\
\left(\mathrm{g}^{235} \mathrm{U}\right)(30 \text { sec. })\end{array}$ & $\begin{array}{c}\text { Weight of } \\
\text { shielding }(\mathbf{k g})\end{array}$ \\
\hline $3 \times 3$ in. $\mathrm{NaI}(\mathrm{Tl})$ & 0.5 & 0.390 & 14.34 & 0.29 & 8.65 \\
\hline $3 \times 3$ in. $\mathrm{NaI}(\mathrm{Tl})$ & 0.75 & 0.244 & 11.65 & 0.24 & 13.82 \\
\hline $3 \times 3$ in. $\mathrm{NaI}(\mathrm{Tl})$ & 1.0 & 0.152 & 9.52 & 0.19 & 19.55 \\
\hline $2 \times 3$ in. $\mathrm{NaI}(\mathrm{Tl})$ & 0.5 & 0.390 & 27.19 & 0.55 & 5.56 \\
\hline $2 \times 3$ in. $\mathrm{NaI}(\mathrm{Tl})$ & 0.75 & 0.244 & 22.20 & 0.45 & 9.08 \\
\hline $2 \times 3$ in. $\mathrm{NaI}(\mathrm{Tl})$ & 1.0 & 0.152 & 18.25 & 0.37 & 13.09 \\
\hline $2 \times 2$ in. $\mathrm{NaI}(\mathrm{Tl})$ & 0.5 & 0.390 & 47.82 & 0.98 & 3.71 \\
\hline $2 \times 2$ in. $\mathrm{NaI}(\mathrm{Tl})$ & 0.75 & 0.244 & 39.10 & 0.80 & 6.06 \\
\hline $2 \times 2$ in. $\mathrm{NaI}(\mathrm{Tl})$ & 1.0 & 0.152 & 32.21 & 0.66 & 8.73 \\
\hline
\end{tabular}

Results presented in Table 4 show that a shielded $3 \times 3$ in. $\mathrm{NaI}(\mathrm{Tl})$ detector gives the best MDA values for ${ }^{238} \mathrm{U}$. However, even with $0.5 \mathrm{in}$. lead shielding, the weight of the $3 \times 3 \mathrm{in}$. detector is $8.65 \mathrm{~kg}$ (or $19.03 \mathrm{lb}$.). At this weight, the probe might be too heavy to be carried by hand. A mobile platform on which the detector and the shield can be mounted could be a solution; however, items measured in holdup tend to be of unusual geometries and subject to space constraints. Using a $2 \times 3 \mathrm{in}$. NaI detector will reduce the weight of the shielding at the cost of degrading the MDA value. The MDA value can be lowered by a factor of 0.707 by doubling the counting time from 30 seconds to 60 seconds.

For routine LEU hold-up measurements at Portsmouth, it is recommended that a shielded $(0.5$ in. thick lead shield) $2 \times 2$ in. $\mathrm{NaI}(\mathrm{Tl})$ detector be used and that data acquisition and analysis be carried out for both $186 \mathrm{keV}$ and $1,001 \mathrm{keV}$ gamma rays. A best value for reporting can be selected based on the uncertainty estimates. Using a larger detector, e.g., $3 \times 3$ in. or $2 \times 3$ in. $\mathrm{NaI}(\mathrm{Tl})$ with a $0.5 \mathrm{in}$. lead shield, is only necessary when performing confirmatory measurements with greater precision.

\subsection{GAIN STABILIZATION OF SCINTILLATION DETECTOR RESPONSE}

Scintillation detector response is temperature dependent and fluctuates as the ambient temperature varies. Aside from the crystal, the photo multiplier tube's (PMT) response also varies with temperature. For hold-up applications, the variation in the detector response must be mitigated using a gain stabilization scheme in the MCA and in the analysis software. A two-point stabilization (zero and gain) scheme is desirable since it guards against a systematic shift as well as a non-linear variation in the gain. However, in modern digital signal processors, satisfactory gain stabilization can be achieved using just a one-point stabilization (no zero stabilization). Two different approaches to gain stabilization are discussed below.

\subsubsection{Gain Stabilization Using an LED-Based Approach}

One stabilization technique uses a light-emitting diode (LED) (Jordanov and Kastner 2006). The LED operates in pulse mode - that is, it periodically produces very short light pulses. The LED light beam is divided by a light splitter. One portion of the beam illuminates a photodiode and the other light beam illuminates the photosensitive part of the PMT. The light traveling to the photomultiplier can be delivered through the scintillation crystal that is optically coupled to the photomultiplier (Figure 16) or through a light guide coupled directly to the photosensitive part of the PMT (Figure 17). The first arrangement 
provides tracking and compensation of the crystal transparency if the wavelength of the LED light is close to the wavelength of the scintillation light.

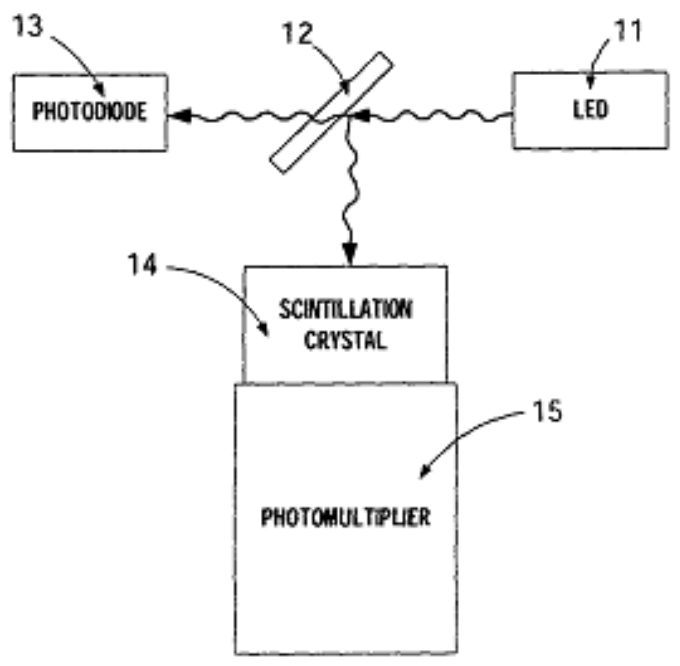

Figure 16. Light pulse tracked through crystal.

The measured radiation interacts with the scintillation crystal and produces a short scintillation light pulse. Both the scintillation light and the LED beam light are subject to the same gain variations in the PMT response caused by variations in temperature. The high voltage (HV) bias applied to the PMT controls the gain and can be used as a gain regulation element.

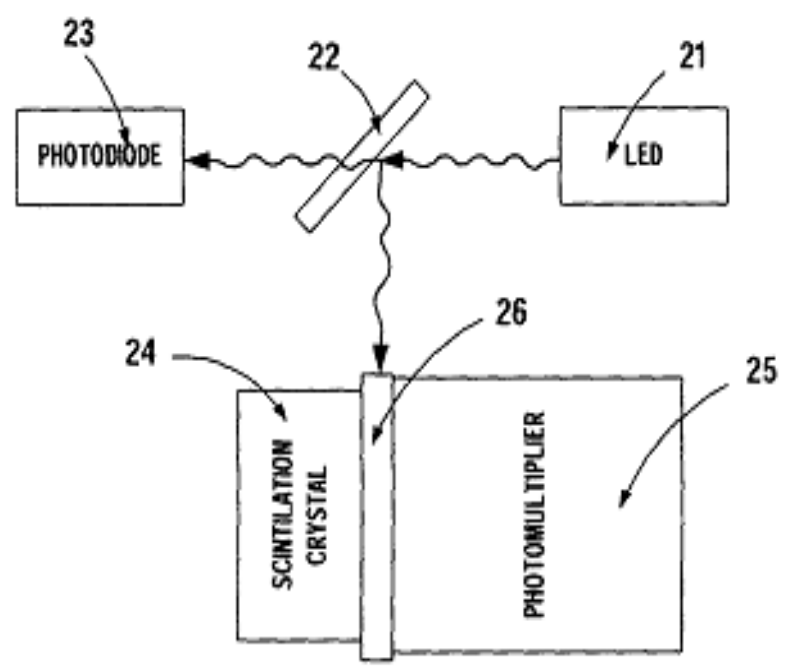

Figure 17. LED light fed directly to the PMT.

Although the gain of the photomultiplier path can be very stable, the response of the scintillation detector (scintillation crystal + photomultiplier path) to the radiation may vary with the temperature. The main source of this is the temperature dependence of the light output of the scintillation crystal. The light output temperature dependence is a fundamental property of the scintillation crystals. For a given scintillation material, this temperature dependence is assumed to be well known, and normalized curves available in the literature are used. The gain adjustment for temperature dependence of the scintillation 
light output is accomplished by using a sensor that provides the temperature of the crystal and a look-up table that gives a corresponding correction factor.

In this approach, no zero stabilization is provided, and the correction for the scintillation light output is only as good as the look-up table used.

\subsubsection{Gain Stabilization Using an ${ }^{241}$ Am Seed in the Scintillation Crystal}

In this approach, a small seed of an ${ }^{241} \mathrm{Am}$ source is attached to the scintillation crystal (Shepard et al. 1997). The ${ }^{241}$ Am source emits an alpha particle, which — when it strikes the detector — causes an event in the detector at a gamma equivalent energy (GEE) of about $3.3 \mathrm{MeV}$. This results in a peak in the spectrum that looks similar to a normal gamma ray photopeak at this energy (Figure 18). The $60 \mathrm{keV}$ gamma ray peak from ${ }^{241} \mathrm{Am}$ can be used for zero stabilization. By monitoring the behavior of the GEE peak and the $60 \mathrm{keV}$ gamma ray peak from the ${ }^{241} \mathrm{Am}$ seed, the system can provide corrections to hold the gamma ray peak of interest into specific channels or ROIs as required. For LEU measurements using $1,001 \mathrm{keV}$, the advantage is that the $3.3 \mathrm{MeV}$ GEE peak from alpha interaction is closer in energy to the $1,001 \mathrm{keV}$ peak than to the $186 \mathrm{keV}$ peak used in HEU campaigns.

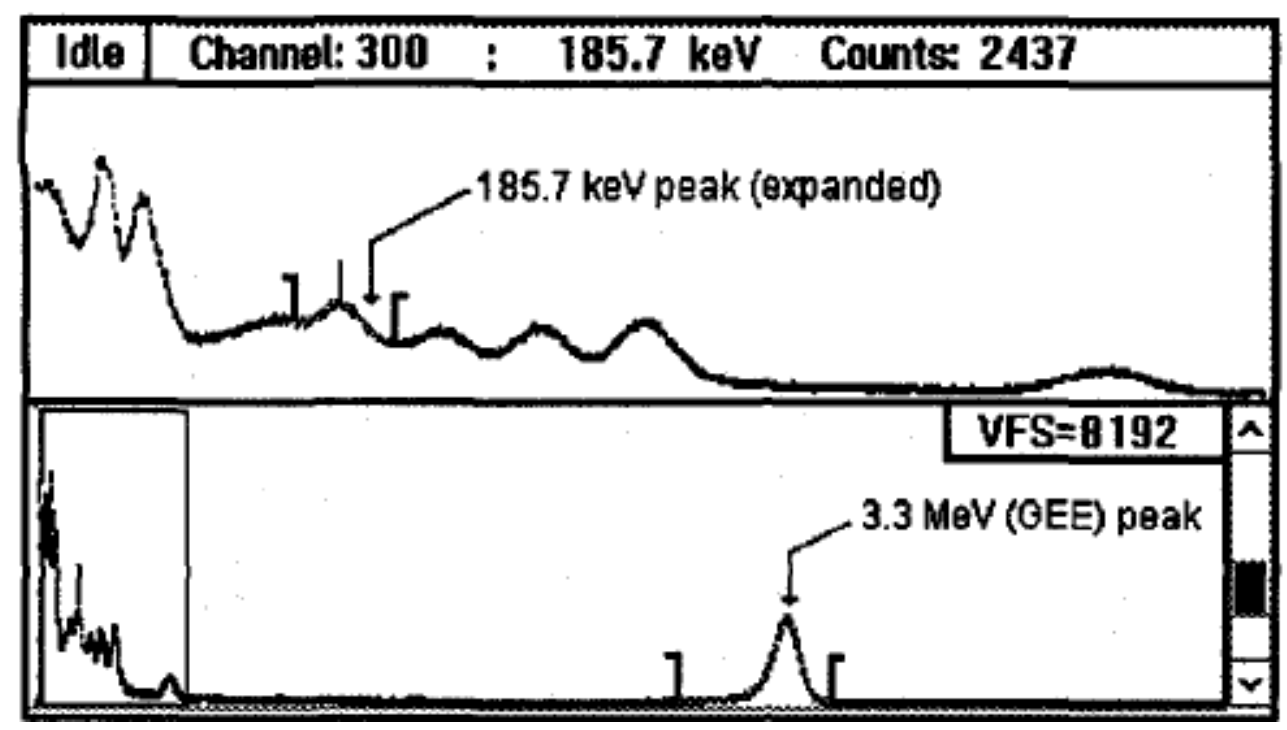

Figure 18. Gain stabilization using the 3.3 MeV GEE peak from ${ }^{241} \mathrm{Am}$ seed.

While the above method seems attractive, it is not without its own problems. Gain variations as a function of temperature are not consistent from one detector and tube combination to the next. This means that the required gain correction factor can only be generated with knowledge of the characteristics of a specific detector-a single correction cannot be applied universally for all detectors. For best results, each detector must be individually characterized. This is the approach used by the International Atomic Energy Agency (IAEA) for their safeguards applications.

Using an ${ }^{241} \mathrm{Am}$ seed to accomplish a two-point stabilization would be the preferred approach. The need for individual characterization can be mitigated with a generalized model of the temperature dependence characteristics of scintillation detectors of a given type and size.

Damage to the scintillation crystals caused by long-term exposure to alpha radiation is another problem to consider. 


\section{HIGH PURITY GERMANIUM DETECTOR RESULTS}

Two different HPGe detectors were evaluated in this work: (1) a liquid nitrogen cooled CANBERRA BE3820 and (2) an electrically-cooled ORTEC Detective. The CANBERRA Broad Energy Germanium detector is a p-type semiconductor detector with a point contact. The point contact electrode allows for a uniform manifestation of the electric field inside the crystal, which enables efficient charge collection. This results in a better energy resolution when compared to a coaxial HPGe detector. The superior energy resolution is very useful while performing isotopic analysis on uranium or plutonium materials.

The experiment configuration for the BEGe detector measurements is shown in Figure 19. The BEGe detector was shielded by ISOCS (In Situ Object Counting System) shields. Graded shielding was used with a tin and copper layer inserted between the cylindrical outer surface of the HPGe detector and the inner surface of the ISOCS lead shield. The source (NBL can) was located at a distance of $40 \mathrm{~cm}$ from the front surface of the detector, coaxial with respect to the detector.

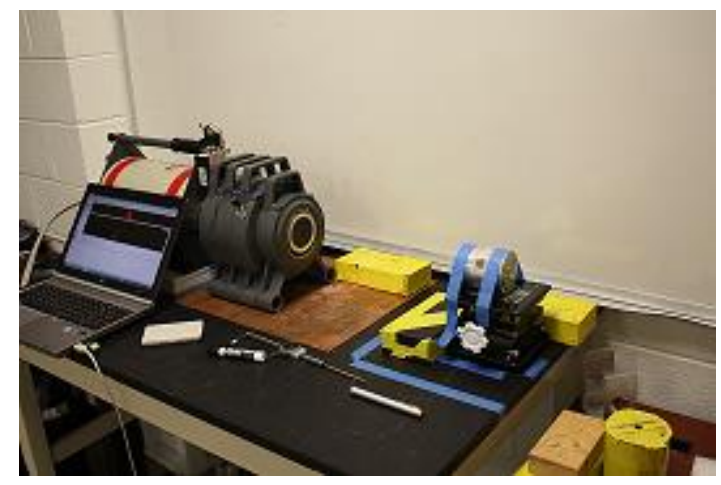

Figure 19. NBL can measurement using the BE3820 detector and ISOCS shield.

The ORTEC Detective is a p-type coaxial HPGe crystal. The electrical cooling enables operation without liquid nitrogen. The Detective is designed for field deployment and is thus rugged and relatively easy to carry.

As a measure of the performance, the energy resolution and count rates are presented below. The energy resolution was tested at various gamma ray energies in the 59.6-1332.5 keV energy range, as shown for each HPGe detector in Figure 20. 


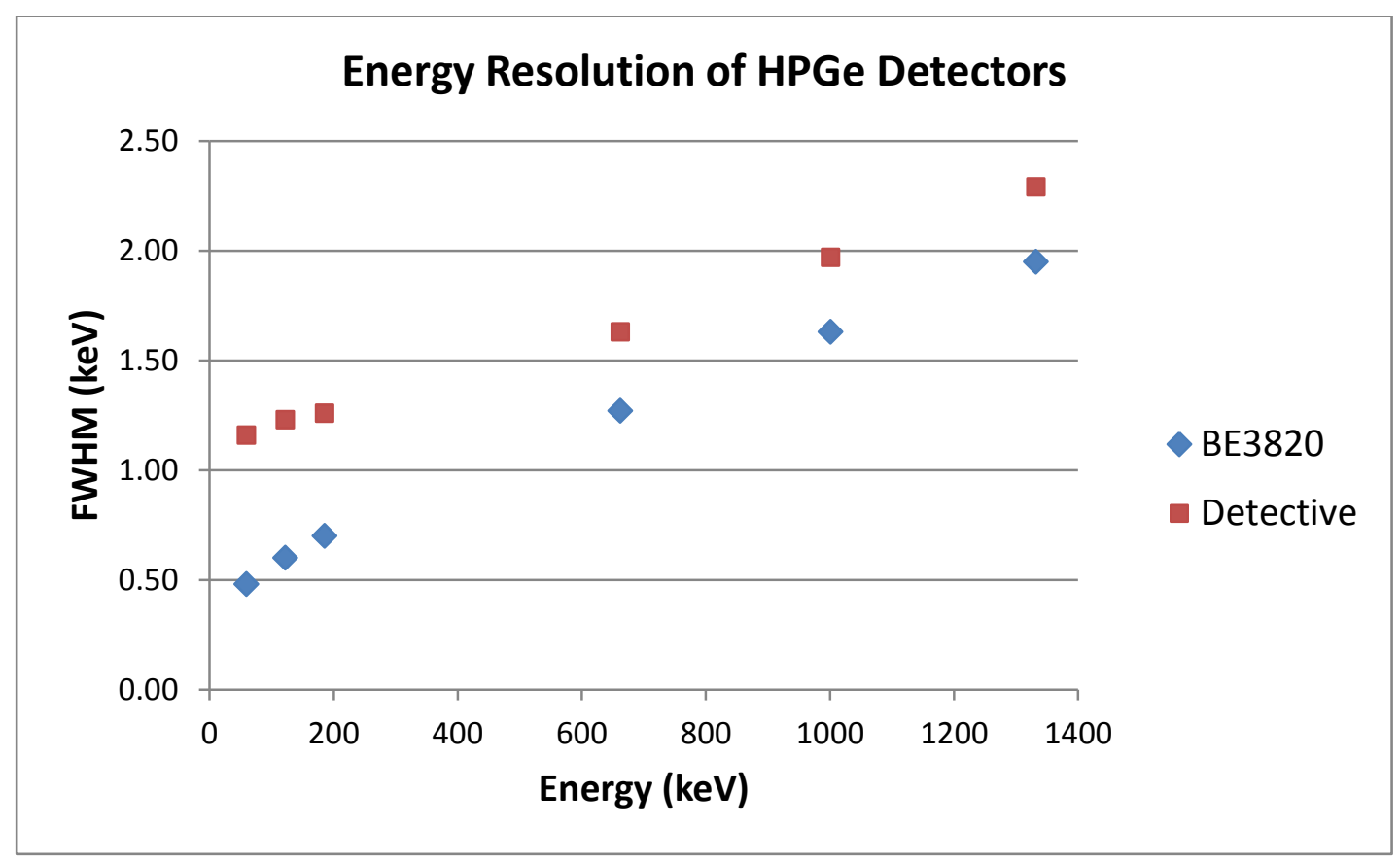

Figure 20. Energy resolution of HPGe detectors.

As with the scintillator detectors, the count rates were measured for each of the NBL standards. The count rate performance as a function of enrichment (atom percentage) of the HPGe detectors is shown in Figure 21.

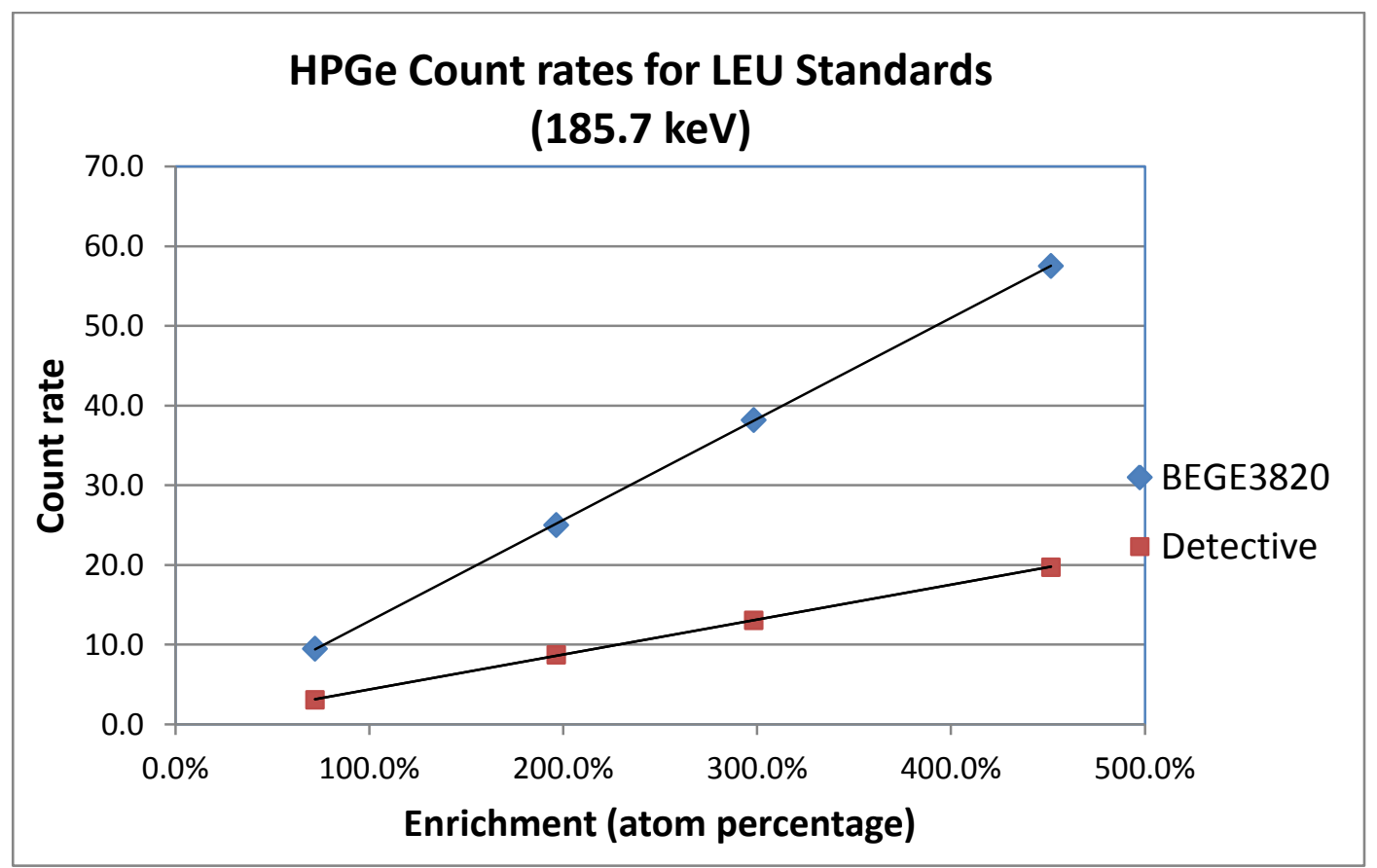

Figure 21. HPGe count rates for LEU standards (185.7 keV). 
The count rates from the BEGe detector are higher because of the larger size of the germanium crystal. The count rates at the gamma ray energy of $186 \mathrm{keV}$ from both detectors are very linear as a function of enrichment, as illustrated by the trend lines in the figure above. A linear fit $(\mathrm{Y}=\mathrm{a}+\mathrm{bX})$ of the data was performed using the Deming curve fitting program (Harker 2012). The fitting coefficients " $a$ " and " $b$ " are given in Table 5 below.

Table 5. Fitting parameters for HPGe data

\begin{tabular}{lccc}
\hline \multicolumn{1}{c}{ Detector } & Coefficient "a" & Coefficient "b" & Reduced $\boldsymbol{\chi}^{2}$ \\
\hline Detective & $-9.490 \mathrm{E}-008 \pm 1.135 \mathrm{E}-004$ & $4.3788 \mathrm{E}+00 \pm 2.11 \mathrm{E}-002$ & 1.276 \\
BE3820 & $5.908 \mathrm{E}-0007 \pm 2.901 \mathrm{E}-004$ & $1.278 \mathrm{E}+001 \pm 5.568 \mathrm{E}-002$ & 8.349 \\
\hline
\end{tabular}

The fitting results show that the Y intercepts (coefficient "a") are very small for the data sets from both HPGe detectors. This is as expected. The reduced $\chi^{2}$ values for the Detective results are excellent. A relatively large reduced $\chi^{2}$ value is observed in the fit results for the BEGe data. The Deming results indicated that the deviation of the fit at the $0.721 \%$ data point was higher than the counting uncertainty by a factor 4 . The possible reasons for this deviation are being investigated.

The results for the HPGe count rates at 1,001 keV are given in Figure 22 below. The higher count rate from the BEGe detector is caused by its larger size.

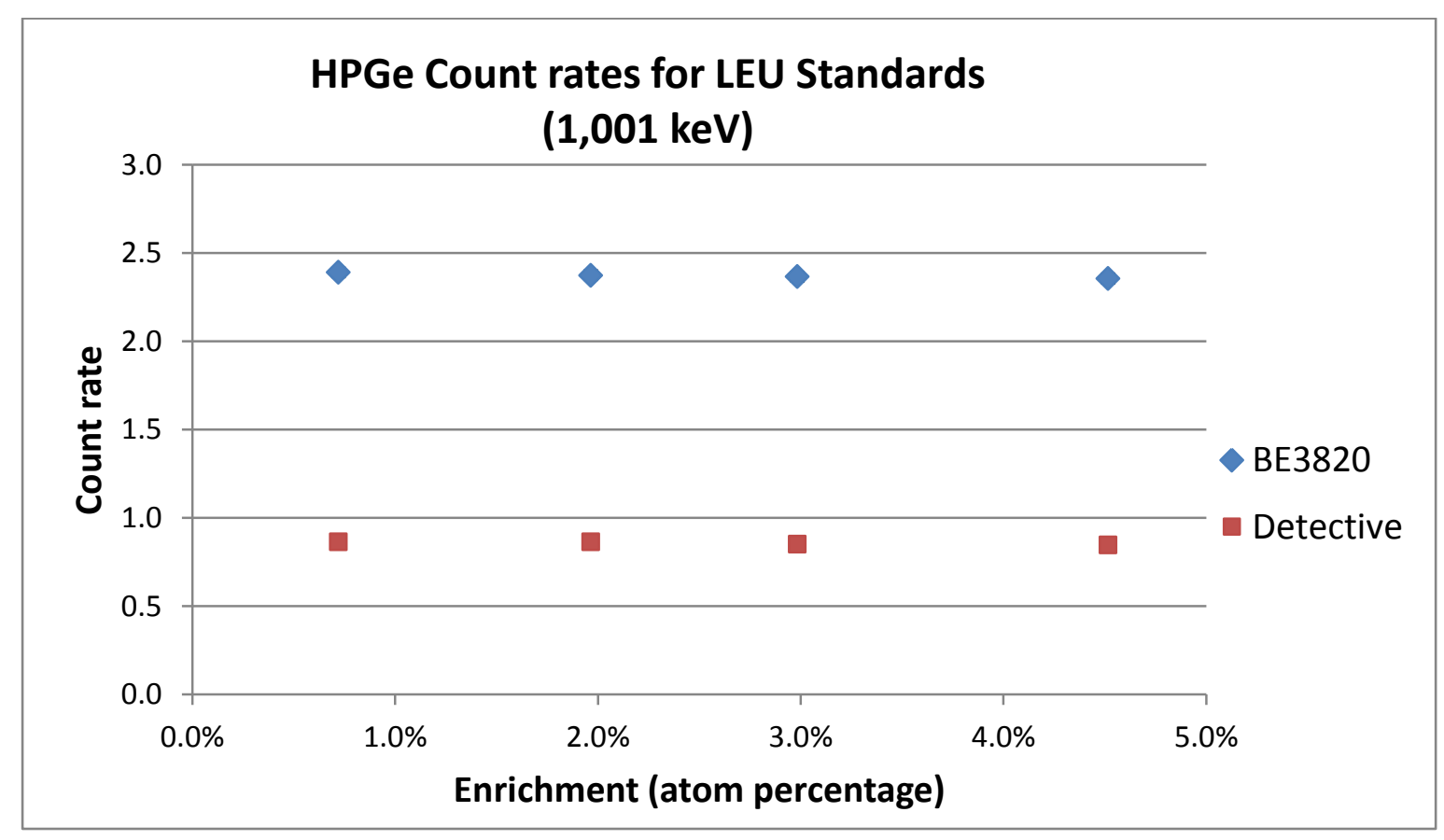

Figure 22. HPGe count rates for LEU standards $(1,001 \mathrm{keV})$.

The Portsmouth plant has several HPGe detectors (BEGe, LEGe, etc.) that can be leveraged for secondary measurements of LEU hold-up. These detectors are mostly liquid nitrogen cooled detectors. Those with smaller dewars (multi-attitude cryostats with 2-day or 5-day supply of liquid nitrogen) can be mounted on a cart or a stand along with the associated shielding. Since the HPGe detectors are to be used for secondary measurements only, one can employ longer counting times (30 minutes) in order to get good counting statistics. Electrically-cooled detectors such as the Detective will certainly be an option in the 
near future. Isotopic codes, including MGAU and FRAM, are currently being adapted to work using data acquired with an electrically-cooled HPGe. 


\section{CONCULSIONS}

Different scintillation detector candidates were evaluated for measuring LEU deposits. Performance criteria included efficiency, energy resolution, and the peak-to-continuum ratios and were considered at the gamma ray energies of interest, namely $186 \mathrm{keV}$ and $1,001 \mathrm{keV}$. The performance was evaluated as a function of uranium enrichment.

The $3 \times 3$ in. $\mathrm{NaI}(\mathrm{Tl})$ detector had the best efficiency, lowest detection threshold for the $1,001 \mathrm{keV}$ gamma rays, the highest peak-to-continuum ratio at $1,001 \mathrm{keV}$, and an adequate energy resolution. However, the shielding around the $3 \times 3 \mathrm{in}$. $\mathrm{NaI}(\mathrm{Tl})$ detector will weigh $8.65 \mathrm{~kg}$ for a thicknesses of just $0.5 \mathrm{in}$. At this weight, the probe will be too heavy to carry by hand. A mobile platform on which the detector and the shield can be mounted could be a solution. The impact of this requirement must be considered by facility operations personnel to determine if this is a practical solution.

For routine LEU hold-up measurements at Portsmouth, it is recommended that a shielded $(0.5$ in. thick lead shield) $2 \times 2$ in. $\mathrm{NaI}(\mathrm{Tl})$ detector be used and that data acquisition and analysis be carried out for both $186 \mathrm{keV}$ and 1,001 keV gamma rays. A best value for reporting can be selected based on the propagated uncertainty estimates. Using a larger detector, e.g., $3 \times 3$ in. $\mathrm{NaI}(\mathrm{Tl})$ with a 0.5 in. lead shield, is only necessary when performing confirmatory measurements with greater precision.

Using a $\mathrm{LaBr}_{3}(\mathrm{Ce})$ detector does not offer any particular advantage for the LEU campaign. For measuring the $186 \mathrm{keV}$ gamma, the shielded ( 0.5 in. thick lead shield) $2 \times 2 \mathrm{in}$. NaI(Tl) detector is more suitable than a $1.5 \times 1.5$ in. $\mathrm{LaBr}_{3}(\mathrm{Ce})$ detector in terms of the MDA that can be achieved. $\mathrm{LaBr}_{3}(\mathrm{Ce})$ will have an advantage in gamma spectrometry applications where there is a need to perform nuclide identification; however, the LEU hold-up at Portsmouth is not this type of application. At the 1,001 keV energy regime, the artifacts from the intrinsic background in the $\mathrm{LaBr}_{3}$ degrade the peak/continuum ratios and will make background subtraction challenging.

It is highly recommended that an MCA that uses a robust gain stabilization scheme be used for the LEU measurements and for all hold-up applications. In the probes used for measuring HEU hold-up based on the signal from the $186 \mathrm{keV}$ gamma, an adequate gain stabilization was effected using the $60 \mathrm{keV}$ gamma

ray peak from an ${ }^{241} \mathrm{Am}$ source attached to the front of the probe. In the case of LEU hold-up, it may be necessary to measure the $1,001 \mathrm{keV}$ gamma ray. A two-point stabilization scheme using an ${ }^{241} \mathrm{Am}$ seed would be ideal.

BEGe detectors are good candidates for performing secondary measurements of LEU deposits. The Portsmouth plant has a number of these detectors along with shielding that can be readily deployed. 



\section{REFERENCES}

"BrilLanCe Scintillators Performance Summary." 2009. Scintillation Detectors Technical Note. Saint Gobain Crystals.

Currie, L. A. 1968. "Limits for Qualitative Detection and Quantitative Determination - Application to Radiochemistry." Analytical Chemistry 40 (March): 586-593.

Harker, B. 2012. Deming Curve Fitting for Windows (version 2.00). Safeguards Science and Technology Group (NEN-1), Nuclear Engineering and Nonproliferation Division, Los Alamos National Laboratory.

Jordanov, V. T., and M. Kastner. 2006. Stabilized Scintillation Detector for Radiation Spectroscopy and Method. US7005646 B1, filed July 24, 2003, and issued February 28, 2006.

Russo, P. A., T. R. Wenz, S. E. Smith, and J. F. Harris. 2000. "Achieving Higher Accuracy in the Gamma-Ray Spectroscopic Assay of Holdup.” Los Alamos National Laboratory Report LA-13699MS.

Shepard, R., S. Wawrowski, M. Charland, H. Roberts, and M. Moeslinger. 1997. "Temperature Stabilization of a Field Instrument for Uranium Measurements." IEEE Transactions on Nuclear Science 44 (3). 

APPENDIX A. EXAMPLE SPECTRA FOR LEU URANIUM STANDARDS 



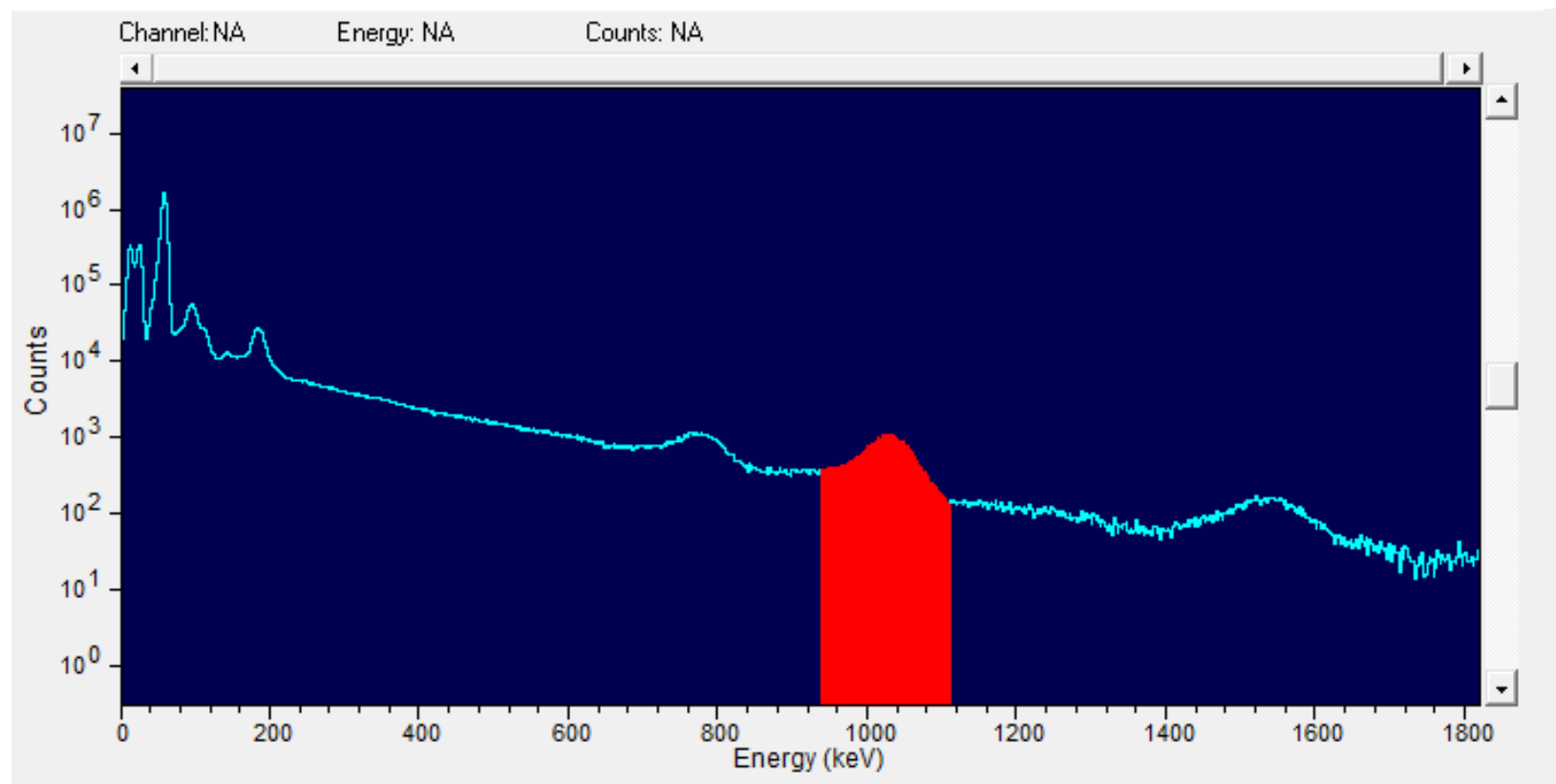

Figure A-1. Spectrum from a $2.98 \%$ enriched uranium standard taken with a $3 \times 3$ in. NaI(TI) detector.

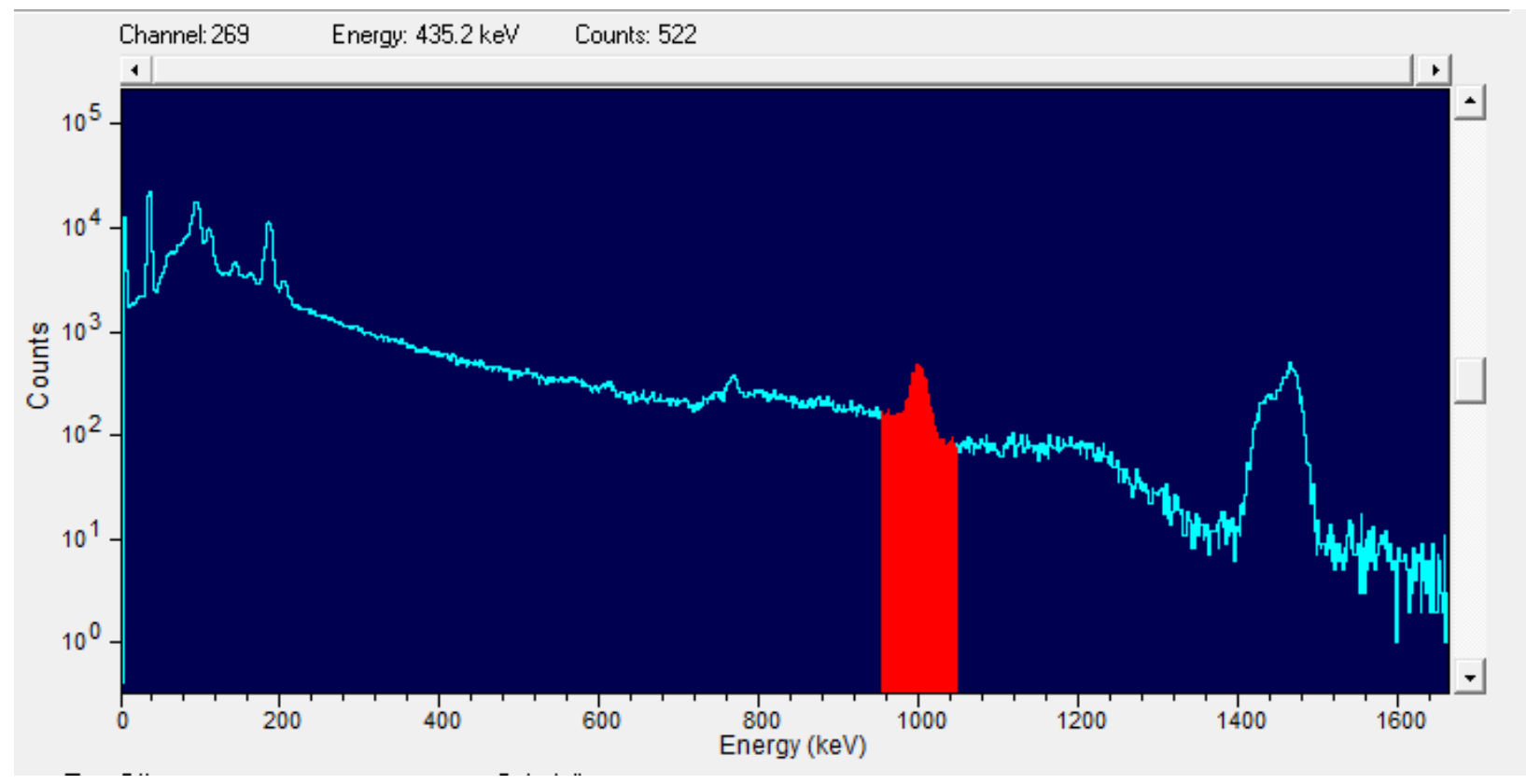

Figure A-2. Spectrum from a $2.98 \%$ enriched uranium standard taken with a $1.5 \times 1.5$ in. $\mathrm{LaBr}_{3}(\mathrm{Ce})$ detector. 


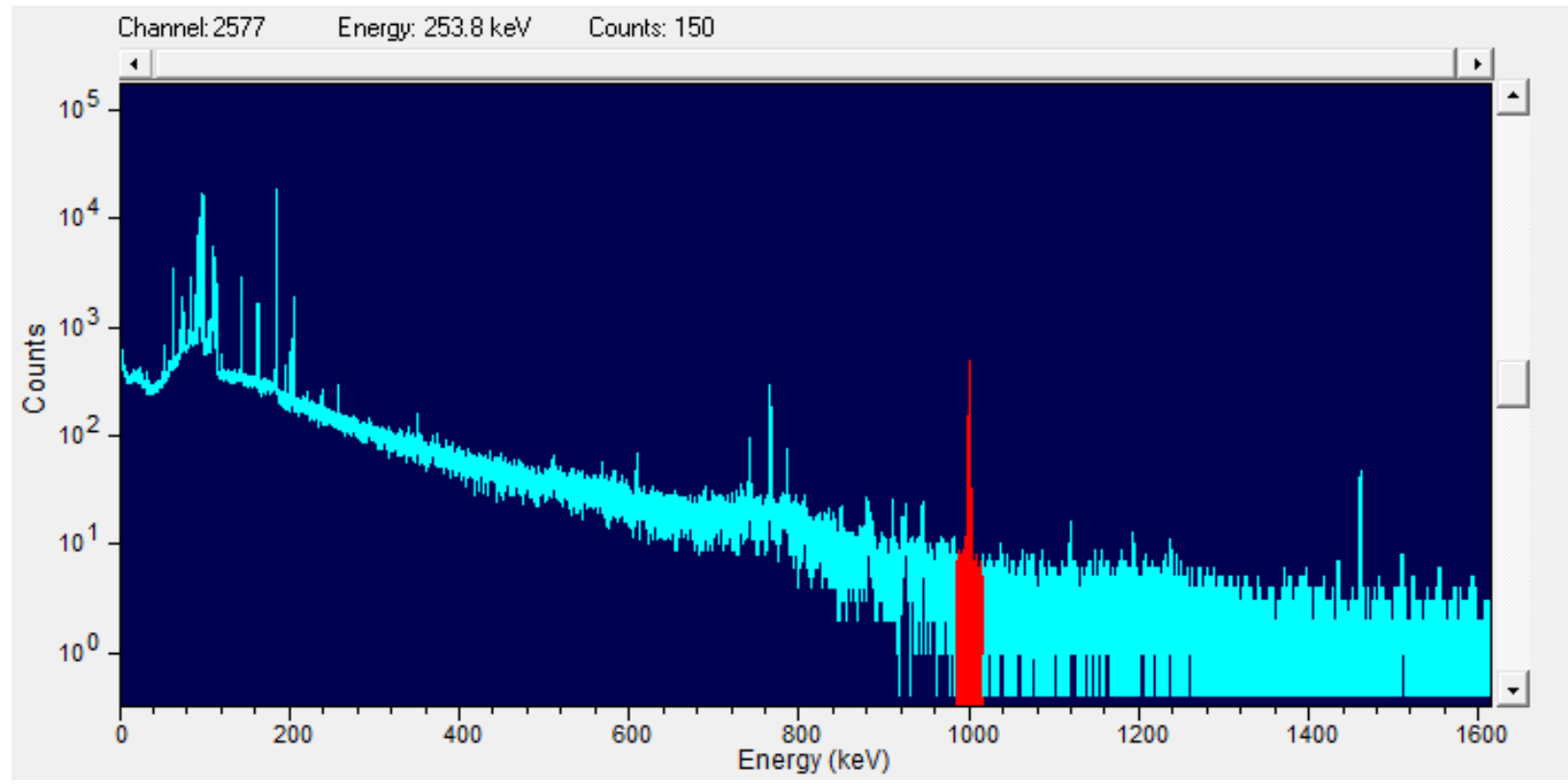

Figure A-3. Spectrum from a $2.98 \%$ enriched uranium standard taken with a BEGe3820 detector. 